\title{
Les complexités hagiographiques, liturgiques et iconographiques d'un livre d'Heures régional (McGill, MS 156)'
}

\author{
HELENA KOGEN
}

Université du Québec à Montréal

Le livre d'Heures McGill, MS 156 n'a jamais fait objet d'une étude scientifique exhaustive, hormis quelques notices plaçant son élaboration en Franche-Comté ou en Bourgogne après 1450. En effet, ce manuscrit offre plusieurs difficultés d'identification et d'interprétation. Ainsi, le caractère composite de ses textes liturgiques, tout en pointant vers l'Est de la France, rend opaque la définition de son usage; son décor, partiellement détérioré et mutilé, ne fut jamais lié à un atelier particulier; son hagiographie se réfère à un horizon cultuel apparemment hétéroclite. Nous tenterons de relever ces défis grâce à une analyse détaillée des dimensions codicologique, hagiographique, liturgique et artistique de ce manuscrit, laquelle mènera à de nouvelles hypothèses concernant l'usage liturgique, les circonstances de l'élaboration et la datation de ce livre d'Heures. De même, nous proposerons d'associer le décor de ce manuscrit à l'atelier d'un des enlumineurs les plus intéressants de l'Est français de la fin du Moyen Âge.

The Book of Hours McGill, MS 156 has never been the subject of an exhaustive scientific study apart from some notices placing its production in Franche-Comté or Burgundy after 1450. In fact, this manuscript includes many challenges of identification and interpretation. While pointing toward the east of France, the composite character of these liturgical texts makes it difficult to define its usage; its illumination, partially deteriorated and mutilated, was never linked to a particular workshop, and its hagiography pertains to a seemingly incongruous religious background. We will attempt to remedy these issues by means of a detailed analysis of the codicological, hagiographical, and artistic dimensions of this manuscript, which will lead to a new hypothesis concerning its liturgical usage, the circumstances of its production, and the date of this Book of Hours. Likewise, we will propose to associate the decoration of this manuscript with the workshop of one of the most interesting illuminators of eastern France during the late Middle Ages.

1. La recherche et la rédaction de cet article ont été rendues possibles grâce à une subvention du CRSH (2014-2018) accordée au projet « Un Catalogue raisonné des livres d'Heures des XV et XVI siècles conservés au Québec », dirigé par Brenda Dunn-Lardeau. Je remercie très sincèrement cette dernière de ses précieux conseils et suggestions concernant le présent article. Je tiens également à exprimer ma reconnaissance à la Bibliothèque des livres rares et collections spécialisées de l'Université McGill et la galerie Les Enluminures dirigée par Sandra Hindman d'avoir gracieusement accordé la permission de reproduire toutes les illustrations contenues dans cet article. 
$\mathrm{L}$ e livre d'Heures McGill, MS 156 est un manuscrit enluminé conservé aux Livres rares et collections spécialisées de cette bibliothèque depuis 1977. Il n'a jamais fait l'objet d'une étude scientifique exhaustive, mis à part une notice de catalogue maison augmentée d'une description sommaire du manuscrit, laquelle plaçait son exécution en Franche-Comté ou en Bourgogne après $1450^{2}$. Ces deux descriptions sont cependant loin de résoudre les multiples problèmes d'identification et d'interprétation que présente ce manuscrit aujourd'hui lacunaire et dont l'état de conservation laisse à désirer. L'étude que nous proposons ci-après tentera de relever ces défis en posant un regard plus nuancé sur les complexités textuelles et cultuelles de ce manuscrit, tout en avançant une hypothèse sur son attribution artistique.

Aucune marque de commanditaire ne permet de définir le moment de réalisation de ce livre d'Heures ; cependant, il porte plusieurs autres marques qui attestent de relectures au fil des siècles. Ainsi, longtemps après sa création, ce livre d'Heures continuait à être utilisé en tant qu'objet usuel vivant : les prières latines ajoutées au $\mathrm{XVI}^{\mathrm{e}}$ siècle $^{3}$ ainsi que plusieurs inscriptions dévotes datant du siècle suivant ${ }^{4}$ le démontrent clairement. Or, dès le début du XIX ${ }^{\mathrm{e}}$ siècle, il change de vocation et devient un objet d'art ${ }^{5}$. En effet, dès sa "redécouverte", en 1829, "dans un monastère de Lausanne ${ }^{6}$ par le libraire antiquaire John

2. Voir la notice manuscrite détaillée rédigée en 1977 par Leszek Wysocki, dossiers de recherche manuscrits, McGill, LRCS. Les hypothèses avancées dans cette notice seront discutées plus loin. En 2013, Didier Méhu publie une notice sommaire basée sur le travail de Leszek Wysocki avec quelques mises à jour d'ordre descriptif. Cependant, cette notice n'analyse pas le contenu textuel et cultuel de ce livre d'Heures ; de même, elle n'offre aucune hypothèse concernant son attribution artistique. Voir Didier Méhu, 31 octobre 2013, «Les livres d'heures manuscrits conservés dans les collections publiques du Québec », Memini 17 (2013), http://memini.revues.org/478, § 483-522.

3. McGill, MS 156, fol. 167-171, voir l'analyse plus loin.

4. McGill, MS 156, fol. $1 \mathrm{r}^{\circ}, 47 \mathrm{r}^{\circ}$.

5. Pour plus d'information sur la « redécouverte » des livres d'Heures en tant qu'objets d'art, voir Christopher de Hamel, «Books of Hours and the Art Market from the Seventeenth Century to the Present Day ", in Books of Hours Reconsidered, éd. Sandra Hindman et James H. Marrow (Londres : Harvey Miller Publishers, 2013), 41-50.

6. Cette provenance, notée deux fois sur les pages de garde du manuscrit, doit être considérée comme fictive, car à l'époque, le canton de Vaud et Lausanne en particulier ne possédait aucun monastère. Les abbayes vaudoises disparurent avec la conquête bernoise et l'arrivée de la Réforme en 1536. Je remercie sincèrement le personnel des Archives de la Ville de Lausanne, et plus particulièrement M. Marcel Ruegg, l'archiviste, pour ces informations. 
Hearne $^{7}$, ce livre d'Heures trouve sa place auprès des collectionneurs aux intérêts et talents artistiques. Notamment, son premier acquéreur connu fut un certain John Parker (1798-1860) ${ }^{8}$, vicaire de Blodwel (Llanyblodwel, Salop) et propriétaire de Sweeney Hall (Shropshire). Peintre aquarelliste, botaniste ${ }^{9}$ et architecte amateur ${ }^{10}$, il est principalement reconnu pour le projet de restauration de l'église médiévale St-Michel de Llanyblodwel (effectuée entre 1847 et 1853) qui témoigne de sa fascination pour l'art gothique et la volonté de le re-créer, en s'inspirant probablement des grands projets néo-gothiques de Violletle-Duc des années 1840 à Carcassonne et à Notre-Dame de Paris. Parmi les multiples éléments architecturaux et décoratifs, c'est la tour de l'église, rebâtie en 1855-1856 selon le modèle de la Cathédrale Notre-Dame de Fribourg, qui en est l'exemple le plus patent ${ }^{11}$. L'achat d'un livre d'Heures témoigne donc de son intérêt actif pour la culture médiévale :

The reviving taste of the Ornamental Enrichment of the works of the Early and Middle Ages, for which the present is distinguished, may be hailed as the dawn of a better judgement, awakening to a just appreciation of beauty and design, where form and harmonious colour may be seen effectively blended. ${ }^{12}$

7. John Hearne, 81 the Strand (m. 1869) fut un libraire-bibliophile et numismate londonien attesté. 8. Sa signature complète est posée au fol. $1 \mathrm{r}^{\circ}$, les initiales se trouvent aux folios $13 \mathrm{v}^{\circ}, 167 \mathrm{r}^{\circ}$ et $171 \mathrm{r}^{\circ}$.

9. La Bibliothèque Nationale du pays de Galles possède une collection de ses créations artistiques, dont plusieurs dessins de fleurs à l'aquarelle. Les marges fleuries du ms. McGill 156 furent-elles particulièrement en accord avec les intérêts artistiques et botaniques de J. Parker?

10. Voir l'obit de John Parker dans Sylvanus Urban, The Gentleman's Magazine and Historical Review 209 (1860) : 676-678.

11. Voir la description détaillée de l'église au registre des bâtiments historiques d'Angleterre : Historic England, «St Michael's Church Llanyblodwel (Grade I) (1307719) », National Heritage List for England, consulté le $1^{\text {er }}$ août 2015, http://list.historicengland.org.uk/resultsingle.aspx?uid=1307719. Voir également John Newman, Shropshire (New Haven : Yale University Press, 2006), 336-337. Les multiples inscriptions pieuses introduites par J. Parker dans la décoration intérieure de l'église, peuvent-elles être rattachées au contenu textuel du livre d'Heures?

12. Proclamation par T. R. Margetts, membre de la Oxford Architectural Society (Oxford, 1845) contenue dans un cahier d'esquisses préparé par J. Parker en vue de la restauration de l'église St-Michel de Llanyblodwel, dans J. Parker, Gothic Designs principally at Blodwel (1841-1849), The National Library of Wales, Drawing Volume Collection, document numérisé sous la côte WlAbNL004441110. 
À la mort de J. Parker, sa sœur Mary Parker (1799-1864), mariée à Baldwin Leighton ${ }^{13}$, elle-même peintre aquarelliste de renommée nationale ${ }^{14}$, hérite de notre manuscrit avec l'ensemble de Sweeney Estate. Son deuxième enfant, Stanley (1837-1901), avocat, parlementaire et antiquaire ${ }^{15}$, en hérite probablement à sa mort, puisque l'ex-libris familial des Leighton avec la signature de Stanley Leighton orne la page de garde du ms. McGill 156. Comme l'atteste un autre ex-libris, ce manuscrit passe, au $\mathrm{XX}^{\mathrm{e}}$ siècle, au professeur Charles Fox, un bibliophile montréalais d'origine britannique, qui le lègue en 1977 à la bibliothèque des Livres rares et collections spécialisées de McGill.

L'histoire moderne du ms. McGill 156 illustre bien le phénomène du Gothic Revival européen et plus particulièrement britannique du XIX ${ }^{e}$ siècle, qui préconise non seulement la thésaurisation de l'art médiéval, mais sa réappropriation à travers des monuments artistiques et architecturaux nouveaux. Les manuscrits enluminés deviennent alors des éléments décoratifs "naturels » des bibliothèques privées appartenant aux collectionneurs prestigieux ; ils sont réemployés en tant qu'instruments d'auto-affirmation pour une aristocratie en quête - souvent fantasmatique - de son passé et de sa place dans une structure monarchique qui, elle-aussi, cherche à réaffirmer ses origines ${ }^{16}$. L'enluminure "à la médiévale ", associée à des «notions telles que la pureté des sentiments, la sincérité et la loyauté ${ }^{17}$, prend d'assaut les genres épistolaires publics et privés. Et surtout, l'exemple de l'église St-Michel de Llanyblodwel à l'appui ${ }^{18}$, ces manuscrits servent de sources d'inspiration puissantes pour la

13. Sir Baldwin Leighton de Loton Hall (1805-1871), $7^{\mathrm{e}}$ baron de Wattlesborough, partageait les intérêts artistiques de la famille Parker et bénéficiait des conseils de son beau-frère pour la restauration dans le style « néo-Normand » des édifices à Alberbury et à Cardeston, voir Newman, 101 et 189.

14. Voir Mary Leighton Collection au Yale Center for British Art, Department of Rare Books and Manuscripts, MSS 16, consulté le 1 août 2015, http://hdl.handle.net/10079/fa/ycba.mss.0016.

15. Voir l'entrée sur Stanley Leighton dans le Dictionary of Welsh Biography, consulté le 2 août 2015, http://wbo.llgc.org.uk/en/s-LEIG-MAR-1799.html. S. Leighton s'intéresse aux travaux artistiques de son oncle et publie une sélection de ses dessins.

16. Voir Sandra Hindman et Nina Rowe, éd., Manuscript Illumination in the Modern Age : Recovery and Reconstruction (Evanston : Northwestern University, 2001). Chapitre «Specimens. Transformations of Illuminated Manuscripts in the Nineteenth Century », 47-101 et plus particulièrement 63-64.

17. Rowan Watson, Les manuscrits enluminés et leurs créateurs (Méolans-Revel : Éditions Grégoriennes, 2004), 138. Voir toute la discussion, 136-139.

18. Tout comme les « restaurations » entreprises par Viollet-le-Duc, le projet de John Parker ne fut pas sans controverse. En effet, peu après sa mort en 1860, les habitants du village de Llanyblodwel 
reconstruction, souvent excentrique, du paysage architectural d'un pays qui redécouvre tout un pan jadis dévalorisé et oublié de son histoire artistique.

Témoin de l'histoire culturelle et artistique de l'Europe médiévale et moderne, le manuscrit McGill 156 mérite bien d'être examiné et analysé en détail.

\section{Le manuscrit}

Le ms. McGill 156 est un livre d'Heures écrit sur parchemin en lettres gothiques de forme, en latin et en français. Il compte 171 feuillets répartis en vingt-trois cahiers à foliotation moderne. De dimensions modestes, il mesure $117 \times 167$ $\mathrm{mm}$. Le texte est disposé sur une colonne d'un nombre de lignes variable en fonction du contenu : soit sur dix-sept lignes pour le calendrier ; sur quinze lignes pour les péricopes et les autres textes qui constituent le cahier 3 ; enfin, seize lignes pour le reste. Le livre a été relié au XX ${ }^{e}$ siècle $^{19}$. La perte de quelques folio ${ }^{20}$ permet de caractériser ce manuscrit comme lacunaire ${ }^{21}$.

Structure interne du manuscrit McGill, MS 156

\begin{tabular}{|c|c|c|}
\hline Cahiers & Folios & Contenu \\
\hline \multirow{2}{*}{$1-2$} & $2-13 \mathrm{v}^{\circ}$ & Calendrier en français \\
\hline \multirow{3}{*}{3} & $14-18 \mathrm{v}^{\circ}$ & Péricopes des Évangiles \\
\cline { 2 - 3 } & $18 \mathrm{v}^{\circ}-20$ & Les VII joies de Notre Dame \\
\cline { 2 - 3 } & $20-21 \mathrm{v}^{\circ}$ & Les VII vers de s. Bernard \\
\hline
\end{tabular}

réaménagèrent l'église tout en gommant la grande partie de sa décoration intérieure. Le projet décoratif de J. Parker fut remis en évidence lors des travaux de restauration en 1960.

19. Voir l'article de Geneviève Samson dans le présent numéro.

20. Les feuillets perdus avant la plus récente reliure : dernier feuillet du cahier 5 (fin de Matines, début de Laudes), le $4^{\text {e }}$ feuillet du cahier 8 (début de Sexte), correspondant à la perte de deux miniatures. Également, le dernier feuillet du cahier 7 (avant le fol. 52 et contenant la fin de Prime des Heures du Saint-Esprit et le début de Tierce) arraché laissant un talon avec des traces de décoration marginale et signifiant la perte d'une troisième miniature.

21. La collation détaillée du manuscrit se trouvera dans le Catalogue raisonné des livres d'Heures conservés dans les collections québécoises, en cours de préparation sous la direction de Brenda Dunn-Lardeau. 


\begin{tabular}{|c|c|c|}
\hline $4-10$ & $22-74 v^{0}$ & $\begin{array}{l}\text { Heures de la Vierge, Heures de la Croix, Heures } \\
\text { du Saint-Esprit }\end{array}$ \\
\hline \multirow{3}{*}{$11-13$} & $75-85$ & Psaumes pénitentiaux \\
\hline & $85-95$ & Litanies et prières \\
\hline & $95 \mathrm{v}^{\circ}-98 \mathrm{v}^{0}$ & Obsecro te \\
\hline $14-16$ & $99-122 v^{\circ}$ & Office des morts \\
\hline $17-18$ & $123-136 \mathrm{v}^{\mathrm{o}}$ & Fin de l'Office des morts \\
\hline \multirow{5}{*}{$19-21$} & $137-140 \mathrm{v}^{\circ}$ & Les XV joies de Notre Dame \\
\hline & $141-143 \mathrm{v}^{0}$ & Les VII requêtes de Notre Dame \\
\hline & $144-147$ & O intemerata \\
\hline & $147 \mathrm{v}^{0}-159 \mathrm{v}^{0}$ & Suffrages \\
\hline & $159 \mathrm{v}^{0}-160 \mathrm{v}^{0}$ & Prières particulières en français \\
\hline \multirow{5}{*}{22} & $161-164 v^{\circ}$ & Suffrages supplémentaires \\
\hline & 165 & Prose de Notre Dame \\
\hline & $165 v^{0}-166$ & Les VIII vers de s. Bernard \\
\hline & $166 v^{0}-167$ & Prière \\
\hline & $167-168 \mathrm{v}^{\circ}$ & Prière $O$ bone Jesu $\left(\mathrm{XVI}^{\mathrm{e}} \mathrm{s}.\right)$ \\
\hline 23 (un binion) & $169-171$ & Prière (XVI ${ }^{e}$ s.) \\
\hline
\end{tabular}

\begin{tabular}{|c|c|c|c|}
\hline & Réglure : & \multicolumn{2}{|c|}{ Langues et types d'écriture : } \\
\hline 17 lignes sur une colonne & & $\begin{array}{c}\text { Rubriques et texte en latin en } \\
\text { gothique de forme }\end{array}$ \\
\hline 15 lignes sur une colonne & & $\begin{array}{c}\text { Rubriques et texte en français } \\
\text { en gothique de forme }\end{array}$ \\
\hline 16 lignes sur une colonne & & $\begin{array}{c}\text { Rubriques en français, texte } \\
\text { en latin en gothique de forme }\end{array}$ \\
\hline & 14 lignes sur une colonne & & $\begin{array}{c}\text { Texte en latin en cursive } \\
\text { bâtarde du XV s. }\end{array}$ \\
\hline
\end{tabular}

Tableau synoptique de la structure interne du ms. McGill 156

Comme le montre le tableau synoptique, ce livre d'Heures articule plusieurs « dossiers » distincts par le choix de la langue du texte et des rubriques, la présentation visuelle et la composition codicologique - notamment, la 
répartition des textes par rapport aux cahiers du manuscrit. Ainsi, les cahiers 1 à 3 du manuscrit contiennent un dossier "mixte » composé d'un calendrier rédigé entièrement en français, les péricopes entièrement en latin, suivies des «Sept joies de Notre Dame » et les « Sept vers de saint Bernard» en latin avec les rubriques en français. Les cahiers 4 à 16 correspondent au " cœur liturgique » du livre d'Heures, présenté entièrement en latin, et réunissent l'Office de la Vierge, les Psaumes pénitentiaux, les Litanies, certaines prières, dont Agnus Dei et Obsecro te, ainsi que la majeure partie de l'Office des morts. Les cahiers 17 à 22 offrent de nouveau un dossier à caractère linguistique " mixte »: la fin de l'Office des morts en latin avec les rubriques en français, quelques prières rédigées entièrement en français, puis une série de textes latins présentés en français comme la prière $O$ intemerata, les suffrages et encore quelques prières privées.

Par ailleurs, le début du cahier 17 correspond à un changement d'unité codicologique : on peut y constater un changement de main de copiste, une modification dans la finesse de l'exécution des initiales, et même une autre qualité, plus médiocre, du parchemin. Ces nouveaux traits codicologiques et artistiques, dont la signification sera discutée plus loin, persistent jusqu'à la fin du cahier 22.

Enfin, il faut noter le caractère particulier du cahier 22 (fol. 161-168) qui contient des textes supplémentaires et " corrigés » : les suffrages consacrés à trois saints dont le dernier, Bernardin de Sienne, faisait l'objet d'un culte très récent, ainsi qu'une version restructurée du texte des «Sept vers » attribué à Bernard de Clairvaux.

Le survol rapide du manuscrit permet de formuler quelques premières hypothèses concernant la structure composite de ce livre d'Heures, manifestement assemblé à partir de non moins de quatre unités codicologiques : cahiers 1-3, 4-16,17-22, plus le cahier 23 qui contient des textes copiés par une autre main bien postérieure à l'époque de l'élaboration du manuscrit ${ }^{22}$. De même, nous pouvons y glaner des renseignements à propos de son commanditaire : une personne francophone, de sexe masculin compte tenu des formes grammaticales employées dans les prières Obsecro te et $O$ intemerata et démontrant certains intérêts cultuels particuliers, dont l'engouement pour les Sept vers de saint Bernard. Dans les pages qui suivent, nous proposons un 
examen plus détaillé des composantes hagiographique, liturgique et artistique de ce livre d'Heures, ayant pour objet d'en préciser l'usage et la provenance.

\section{L'hagiographie dans le ms. McGill 156}

La notice détaillée du ms. McGill 156 rédigée par Leszek Wysocki situe le lieu d'exécution de ce manuscrit entre la Bourgogne et la Franche-Comté dans les années suivant 1450, justifiant cette identification par la présence de saints tels que Fiacre, Bénigne, Claude de Besançon dans le calendrier, ainsi que la mention de Bernardin de Sienne, canonisé en 1450, dans les suffrages ${ }^{23}$. Didier Méhu y ajoute la Champagne ${ }^{24}$. L'étude plus détaillée de la galerie de saints protecteurs s'articulant entre le calendrier, les litanies et les suffrages, tentera de préciser ou de nuancer cette attribution.

D'emblée, plusieurs outils critiques permettent de situer le ms. McGill 156 par rapport à la liturgie de deux diocèses principaux de la région concernée : celui de Besançon en Franche-Comté 25 et le diocèse "bicéphale » de Langres réunissant des terres en Champagne et en Bourgogne ${ }^{26}$. Ce manuscrit doit également être placé dans un contexte français et européen plus large ${ }^{27}$. Toute

\section{Wysocki, 1.}

\section{Méhu, $\$ 493$.}

25. Romain Jurot, L'ordinaire liturgique du diocèse de Besançon (Besançon, Bibl. Mun., ms. 101). Texte et sources (Fribourg : Éditions universitaires Fribourg Suisse, 1999). Cette monographie bien documentée offre une étude diachronique minutieuse des traditions liturgiques du diocèse et de son chef-lieu, la ville de Besançon.

26. Jacques Lauga, Les manuscrits liturgiques dans le diocèse de Langres à la fin du Moyen Âge. Les commanditaires et leurs artistes, Thèse doctorale, 3 vols. (Paris : Université Paris IV, 2007). Bien que consacrée en large partie à l'histoire du livre et à l'histoire de l'art, la recherche effectuée par Lauga a permis de réfléchir aux questions d'usage liturgique et de critères de localisation des manuscrits produits dans le duché de Bourgogne, et dont le résultat fait partie des annexes du tome 3, pages 53-63. Le diocèse de Langres s'étendait à l'époque aux villes comme Dijon, Langres, Châtillon, Bar-sur-Aube, Chaumont - voir Lauga, $1: 30$ et $3: 223-225$ pour quelques cartes.

27. La base de données Calendoscope, élaborée par Denis Muzerelle et hébergée depuis 2013 par l'Institut de recherche et d'histoire des textes à Paris, réunit un corpus constitué de quelque 515 calendriers français et européens et permet de confronter le contenu hagiographique de notre livre d'Heures aux occurrences des célébrations de saints clairement identifiées du point de vue géographique et chronologique. Voir http://calendoscope.irht.cnrs.fr/accueil. On doit y ajouter la base de données 
analyse doit cependant tenir compte de l'existence de ses unités codicologiques et en évaluer les modifications éventuelles.

\subsection{Le calendrier}

Le calendrier (fol. $2 \mathrm{r}^{\circ}-13 \mathrm{v}^{\circ}$ ) occupe l'intégralité de la première unité codicologique relevée dans le manuscrit ${ }^{28}$. Il a la particularité d'être entièrement en français avec quelques picardismes (par exemple, Michiel pour Michel, Ladre pour Lazare) et de bénéficier d'une mise en page plus espacée que le reste du manuscrit. Ce calendrier n'est pas particulièrement peuplé, certains mois n'offrant que quelques dates festives ${ }^{29}$. Par ailleurs, on y trouve des erreurs de transcription dans les chiffres d'or au début des mois d'août et de décembre. Certaines fêtes apparaissent à des dates inusitées qui doivent également être considérées comme des erreurs de transcription. Les fêtes majeures sont notées à l'encre rouge.

La plupart des fêtes se rapporte aux grands festivals du temporal, avec l'absence notable de la fête de la Transfiguration célébrée le 6 août à partir de 1456, ou bien aux saints de l'Église universelle. Cependant, la présence de quelques saints moins connus, et surtout le choix des dates consacrées à la célébration de leur culte, associent ce calendrier à des traditions régionales propres à l'Est de la France et la Franche-Comté - les diocèses de Troyes en Champagne, Langres, Besançon en particulier, ainsi que les diocèses limitrophes comme Toul, Chalon-sur-Saône, Autun ${ }^{30}$, etc.

Beyond Use élaborée par Gregory Clark qui recense les éléments liturgiques et hagiographiques dans près d'un millier de livres d'Heures. Voir http://art.sewanee.edu/gclark/beyond_use.

28. Didier Méhu signale la présence de ces trois unités codicologiques, sans pour autant pousser plus loin l'analyse ; par ailleurs, il propose l'identification erronée du début de la 3e unité (fol. 137 au lieu du fol. 123 dans le manuscrit). Méhu, $\$ 485$.

29. Notamment, cinq fêtes seulement au mois de mars.

30. Notons ainsi l'Octave de Jean l'Évangéliste (3 janvier, Langres et Troyes), Gérard de Toul (23 avril, Langres et Toul), Gengou (11 mai en rouge, fête célébrée dans l'Est français), Didier de Langres (23 mai, Langres, Besançon, Chalon-sur-Saône), la Passion de Ferréol et Ferjeux (16 juin, fête célébrée dans l'Est français), Antide de Besançon (17 juin, Langres et Besançon), Marguerite (13 juillet, Langres et Toul), la Couronne de Notre Seigneur (11 août, Besançon et Troyes), Mammès de Césarée (17 août en rouge, Besançon, Langres, Autun), Bernard de Clairvaux (20 août, Langres et Chalon-sur-Saône), Louis de France ( 25 août, fête célébrée dans l'Est français, mais non pas à Besançon), Fiacre de Breuil (30 août, fête célébrée dans l'espace français mais non attestée à Besançon), Marcel évêque de Chalons-sur-Saône 
À côté de ces fêtes plus communes, on trouve des références à des cultes plus locaux. Ici, les diocèses de Troyes et de Langres paraissent les mieux représentés, bien que de manière différente : pour Troyes, le calendrier cite plusieurs saints locaux ${ }^{31}$, tandis que dans le cas de Langres, il s'agit plutôt de dates de célébration particulières pour ce diocèse ${ }^{32}$.

Quelques dates peuvent être considérées comme particulières au diocèse de Besançon, surtout si l'on se fie à la liste établie par Victor Leroquais que la base de données Calendoscope semble contredire en signalant des cultes plus génériques pour ces mêmes dates ${ }^{33}$.

Même si les influences troyenne et langroise sont bien perceptibles dans ce calendrier, tout comme, dans une moindre mesure, l'influence bisontine, certains cultes pourtant essentiels pour ces diocèses brillent par leur absence : les dédicaces aux cathédrales diocésaines, le culte d'Amâtre d'Auxerre pour les diocèses de l'Est français, de même que le culte des évêques bisontins pour la Franche-Comté. Par contre, on y trouve des cultes étrangers à l'ensemble des régions discutées, qui peuvent être considérés comme des dévotions personnelles du commanditaire : le culte de Robert de Turlande, abbé de la Chaise-Dieu près de Brioude en Auvergne, célébré le 24 avril ; le culte de Boniface pour le 14 mai, une date propre aux traditions monastiques; le culte

(4 septembre, fête célébrée dans l'Est français), Léger (2 octobre, fête célébrée en France), Léonard de Corbeny (15 octobre, fête célébrée dans l'Est français), Berchaire de Hautvillers (16 octobre, Langres et Troyes, fête non attestée à Besançon), Lazare de Marseille (17 décembre, Troyes, Besançon, Autun).

31. Notamment, Fraubert de Troyes (cependant, avec une erreur de transcription le mettant le 8 janvier au lieu de la date correcte, le 7 janvier), Guillaume de Troyes (10 janvier), Savinien de Troyes (24 janvier), Savine de Troyes (29 janvier), Prudence de Troyes (6 avril), Eutrope de Saintonge (30 avril ; selon Leroquais, cité dans Lauga, $3: 60$, il s'agit d'une fête propre au diocèse de Troyes ; Calendoscope propose également plusieurs occurrences parisiennes, France de l'Est, France du Sud), Hélène de Troyes (4 mai), Loup de Troyes (29 juillet, fêté à Langres le 28 juillet).

32. Ainsi, ce calendrier contient Grégoire évêque de Langres (4 janvier), la translation de Didier de Langres (notée le 18 janvier au lieu du 19, la date reconnue), Victor de Troyes (la date du 26 février est propre au diocèse de Langres, celle du 25 février est fêtée à Troyes), Alexius (16 juillet est une date particulière au diocèse de Langres, tandis que ce saint est fêté le 15 juillet à Troyes et le 17 juillet ailleurs en France), la translation de Mammès (10 octobre).

33. Tels sont les cas de Claude de Besançon (6 juin, la date propre au diocèse de Langres étant le 5 juin), la translation de Benoît (11 juillet), Crespin (25 octobre), Quentin (31 octobre), Brice de Tours (13 novembre). Voir Leroquais, cité dans Lauga, $3: 60$. En ce qui concerne Valier de Langres (23 octobre), Calendoscope confirme son occurrence unique pour le diocèse de Besançon. 
d'Yves Hélory de Tréguier, un saint breton fêté le 19 mai ; le culte de Juste d'Alcalá le 6 août, un martyr espagnol dont le seul lieu de culte à l'extérieur de l'Espagne est Narbonne ${ }^{34}$; enfin, la date du 31 août proposée pour Lazare est particulière pour la tradition marseillaise.

Le calendrier du ms. McGill 156 contient quelques datations manifestement erronées $^{35}$. La présence de ces leçons fautives affaiblit la signification des dates particulières et exclusives relevées dans ce calendrier : s'agit-il de marqueurs de cultes locaux, ou bien de moments d'inattention du scribe ? Compte tenu de ces arguments, les affinités troyennes du calendrier paraissent plus solides que celles pour les autres diocèses mentionnés. Enfin, ce calendrier propose deux dates pour la fête de Barbe de Nicomédie : la nouvelle date du 4 décembre et la « vieille» date du 16 décembre, mentionnée dans la Légende dorée.

\subsection{Les litanies}

Les litanies (fol. $85 \mathrm{r}^{\circ}-89 \mathrm{v}^{\circ}$ ) font partie de la deuxième unité codicologique du ms. McGill 156 et proposent quelques nuances importantes par rapport au calendrier. Premièrement, elles maintiennent la dimension " picarde » de l'hagiographie de ce manuscrit, avec la mention de saints comme Bénigne, Didier, les martyrs Vallier, Mammès (son nom est marqué d'une croix en cursive), Gengou, et également Géômes (Gemini) - martyrs particulièrement vénérés dans le diocèse de Langres. Un " groupuscule » des saints « marseillais », formé par la mention de Lazare de Béthanie, Marthe et Marie-Madeleine, est peutêtre à associer à la Cathédrale Saint-Lazare d'Autun. Une autre « famille » peut faire référence à l'abbaye bénédictine jurassienne de Condat et sa Cathédrale Saint-Claude : Eugend, le fondateur de l'abbaye, se trouve dans la litanie, ainsi que Claude de Besançon (confondu à l'époque avec un saint abbé de Condat portant le même nom) et Maurice d'Agaune, saints particulièrement vénérés dans cette abbaye. Par ailleurs, notons l'abondance des « saintes vierges » citées dans la litanie : vingt-trois en tout, dont Geneviève, la patronne de Paris. Enfin,

34. Doit-on l'associer au culte de Vincent de Saragosse, un saint très populaire en France et ailleurs?

35. Ainsi, Valérien apparaît le ler avril au lieu du 14 avril, date qu'il partage avec Tiburce ; Quiriace est marqué le 5 mai au lieu du 4 mai, Symphorien le 21 août au lieu du 22 août. Le cas le plus intéressant est celui de Bénigne de Dijon, célébré le $1^{\mathrm{er}}$ novembre à Besançon, le 2 novembre à Langres, le 5 novembre à Autun; pour la date de 3 novembre proposée dans le ms. McGill 156, Calendoscope cite une seule occurrence, un bréviaire à l'usage de Langres (XVe siècle), Paris, BnF lat. 1303. 
contrairement au calendrier, aucun saint particulier au diocèse de Troyes n’apparaît dans les litanies du ms. McGill 156.

Par contre, c'est la dominante bisontine qui apparaît le plus clairement dans ces litanies. La galerie des saints bisontins, assez éparse dans le calendrier, se voit étoffée par la longue liste des saints évêques : Donat, Lin, Nizier, Protade, Silvestre, Anatoile, Aignan ${ }^{36}$ sans oublier Claude et Antide déjà mentionnés dans le calendrier ; les martyrs Ferréol et Ferjeux occupent une place de choix tout comme Maimboeuf, Agapit, Irénée de Lyon et, bien sûr, Vincent de Saragosse dont les reliques importantes se trouvaient à Besançon ; parmi les abbés - Ermenfroy de Cusance, Lautain de Moisnay.

\subsection{Les suffrages}

Les suffrages font partie de la troisième unité codicologique du manuscrit McGill 156 et s'articulent en deux séries. La première (fol. $147 \mathrm{v}^{\mathrm{o}}-159 \mathrm{v}^{\circ}$ ) offre des prières à Notre Dame, la Trinité, dix-neuf saints et quatre saintes ; la seconde (fol. $161 v^{\circ}-164 \mathrm{r}^{\circ}$ ) y ajoute Vincent de Saragosse, Claude de Besançon et Bernardin de Sienne. Les saints de la première série appartiennent tous à l'Église universelle, sauf Bénigne de Dijon et Fiacre de Breuil dont le culte se limite à l'Est français, de même que le protomartyr Étienne, cité juste après les apôtres (fol. 151 $)^{37}$, qui est d'ailleurs le seul à suggérer une connotation proprement bisontine $^{38}$. Cette connotation bisontine, les suffrages « supplémentaires » la renforcent considérablement en citant deux autres saints particulièrement vénérés à Besançon : Claude de Besançon ${ }^{39}$ et Vincent de Saragosse ${ }^{40}$. Il faut

36. Voir le cas particulier du culte d'Aignan, l'un des «fondateurs de l'Église de Besançon ", dans Jurot, 140 .

37. Dans les litanies, il apparaît premier dans la série des « saints martyrs » tout juste après les apôtres, les disciples et les « saints innocents».

38. Patron du diocèse, il fut objet d'un culte fervent : la cathédrale Saint-Étienne conservait ses reliques et pratiquait de multiples fêtes en son honneur. Jurot, 146-149.

39. Jusqu'à une époque très récente, Claude de Besançon (attesté au VI ${ }^{\mathrm{e}}$ siècle) fut confondu avec Claude, l'abbé de Condat (Saint-Oyend). Son culte et sa fixation à la date du 6 juin remontent au milieu du XIII ${ }^{e}$ siècle et, pour le diocèse de Besançon, l'institution officielle de l'office fut effectuée le 7 mai 1440. Voir Jurot, 135.

40. Les reliques de ce saint espagnol furent offertes à l'Église de Besançon par Charles le Chauve pour être déposées dans les deux cathédrales diocésaines, Saint-Jean et Saint-Étienne. Jurot, 152-153. 
cependant prendre en compte la popularité universelle des trois saints précités, ce qui réduit la pertinence de l'attribution géographique limitée au diocèse de Besançon.

\subsection{Les lignes de force hagiographiques du calendrier et la datation du manuscrit}

Considérés dans leur ensemble, les éléments hagiographiques du ms. McGill 156 semblent osciller entre l'Est français (calendrier, suffrages de la première série) et la mouvance bisontine (litanies, suffrages de la deuxième série). Une vénération particulière peut être constatée pour le protomartyr Étienne (en rouge dans le calendrier, cité de façon très avantageuse dans les litanies et les suffrages) ; pour Claude de Besançon, Vincent de Saragosse, Médard (et Gildard) de Noyon, Bénigne de Dijon (calendrier, litanies, suffrages) ; quant à Gengou, Didier de Langres, Mammès de Césarée, ils apparaissent dans les litanies et en rouge dans le calendrier.

Un traitement particulier est réservé à Bernard de Clairvaux, grand promoteur du culte marial dès ses premiers écrits, réformateur de l'ordre bénédictin (fondateur de l'ordre de Cîteaux) et l'un des saints patrons de la Bourgogne car natif de Dijon. Il apparaît dans le calendrier (20 août) mais nulle part ailleurs dans l'hagiographie du ms. McGill 156. Par contre, le texte des Sept (huit) vers de Saint Bernard est recopié deux fois et bénéficie d'une mise en valeur visuelle particulière. D’autres saints associés à l'ordre bénédictin apparaissent dans l'hagiographie du ms. McGill 156 : Maur, disciple de Benoît (calendrier, 15 janvier et suffrages); Scholastique (10 février), sa sœur et première moniale bénédictine ; Benoît de Nursie lui-même ; Géômes (dans la litanie) et Vincent de Saragosse. Cependant, ces éléments ne paraissent pas suffisants pour rattacher le ms. McGill 156 à une tradition monastique.

La synthèse doit s'arrêter là : les composantes hagiographiques du ms. McGill 156 doivent être considérées comme une série dynamique et mouvante, et non comme un ensemble homogène. L'absence de corrections dans le corps des textes, les ajouts de suffrages "supplémentaires " et d'une version modifiée du texte de Bernard de Clairvaux définissent l'hagiographie de ce manuscrit comme une compilation dont l'usage réel est difficilement saisissable. Les affinités troyennes et, dans une moindre mesure, langroises et bisontines du calendrier, le ton plus neutre de la première série des suffrages, 
ainsi que la dominante nettement bisontine perceptible dans les litanies et les suffrages «supplémentaires » placent le ms. McGill 156 à l'intérieur d'un vaste «corridor lotharingien ${ }^{41}$ dans lequel même les saints « marseillais » trouvent une place.

Du point de vue chronologique, l'addition des suffrages à Bernardin de Sienne canonisé le 24 mai 1450 et l'absence de la fête de la Transfiguration universellement instaurée par le Pape Callixe III en 1456 constituent une balise chronologique assez concrète, du moins pour les suffrages « supplémentaires » et l'assemblage final du manuscrit. Le cas de Claude de Besançon paraît plus nuancé. Ce saint, pourtant très populaire, est oublié dans la première série des suffrages et n'apparaît qu'une seule fois dans le calendrier (6 juin en noir), en plus d'être cité très bas dans la liste des « saints confesseurs» des litanies, pourtant très marquées par la tradition cultuelle bisontine (7e position avant la fin). Peut-on lier ces faits à l'institution tardive (1440) de la fête de Claude à Besançon et considérer l'hagiographie du ms. McGill 156, surtout le calendrier et les litanies, comme témoins des traditions cultuelles antérieures à cette date? Quoi qu'il en soit, l'absence de Bernardin de Sienne dans le calendrier, les litanies et la première série de suffrages situe la majeure partie des textes de ce manuscrit dans les années précédant l'an 1450.

\section{Le contenu liturgique}

\subsection{Les Heures de la Vierge}

La composante liturgique principale du livre d'Heures, l'Office de la Vierge (fol. $22 \mathrm{r}^{\circ}-74 \mathrm{v}^{\circ}$ ), ne permet pas de résoudre entièrement la question de l'usage. L'analyse comparée de la structure de ce texte avec les modèles proposés par Erik Drigsdahl ${ }^{42}$ a permis d'identifier la plupart des éléments de l'Office comme appartenant à l'usage du diocèse de Besançon. Cependant, plusieurs

41. Expression de Gregory Clark dans son article « Beyond Saints : Variant Litany Readings and the Localization of Late Medieval Manuscript Books of Hours - The d'Orge Hours ", in Books of Hours Reconsidered, éd. Sandra Hindman et James H. Marrow (Londres : Harvey Miller Publishers, 2013), 228. 42. Voir l'Annexe I : le tableau synoptique des Heures de la Vierge dans le ms. McGill 156 et le modèle relevé par le regretté Erik Drigsdahl. Toutes les identifications effectuées dans ce chapitre ont été établies à l'aide des données du site de Drigsdahl, http://www.chd.dk/use/hv_besancon.html et autres usages. Au moment de la rédaction de cet article, le site était discontinué. Espérons que le Center 
variantes intéressantes ont été relevées, témoignant des particularités de son usage liturgique. Quelques pertes d'éléments textuels, notamment à la fin de Matines et de Complies, introduisent un facteur de doute supplémentaire.

La formule liturgique choisie pour ce manuscrit est celle des Heures mixtes : chaque heure liturgique des Heures de la Vierge est agrémentée par les incipit des Heures de la Croix et des Heures du Saint-Esprit, mis en valeur par une rubrication et, parfois, par une décoration marginale. Ainsi, les Matines (fol. $\left.22 \mathrm{r}^{\circ}-36 \mathrm{r}^{\circ}\right)$ s'ouvrent par une page décorée et enluminée représentant l'Annonciation. Leur structure liturgique suit entièrement l'usage de Besançon. Plus concrètement, à côté des éléments génériques comme l'hymne Quem terra pontus, les Psaumes 94 (Venite exultemus Domino), 8 (Domine Dominus noster) et l'hymne de saint Ambroise, on trouve les lectiones particulières à la liturgie bisontine : la première leçon $O$ mater virgo virginum, suivie du répons Sancta et immaculata; la deuxième leçon O stella maris et son répons Beata es Maria; enfin, la troisième leçon $O$ fili caste virginis, suivie du répons Felix namque es. La fin de l'hymne de saint Ambroise manque ; par ailleurs, l'ajout des Matines de Sainte Croix et du Saint-Esprit n'a pas été prévu.

Malgré la perte de la page enluminée contenant le début des Laudes (probablement, une Visitation), le reste de l'ensemble textuel de cette heure est intact $\left(\right.$ fol. $\left.37 \mathrm{r}^{\circ}-45 \mathrm{r}^{\circ}\right)$, ce qui permet de constater sa conformité au modèle bisontin, à l'exception du capitulum In omnibus requiem, plutôt caractéristique de l'usage de Mâcon et de Sens, ainsi que des ordres religieux (notamment clunisien, cistercien et carmélite). Fait inusité, les Laudes de la Vierge sont ici suivies des Matines de Sainte Croix et du Saint-Esprit (fol. 45v $\left.\mathrm{v}^{\circ}-47 \mathrm{r}^{\circ}\right)$. Une riche décoration marginale, aujourd'hui partiellement endommagée ${ }^{43}$, sert à mettre en valeur ces textes.

L'heure de Prime (fol. $47 \mathrm{v}^{0}-51 \mathrm{r}^{\circ}$ ) s'ouvre par une page décorée et enluminée d'une image de la Nativité. Sa structure ressemble à celle du modèle bisontin, à deux exceptions notables : le capitulum $A b$ initio et ante secula et l'oraison Adsit nobis quesumus domine devraient normalement faire partie de l'heure de Tierce. L'incorporation du capitulum $A b$ initio correspond plutôt

for Håndskriftstudier I Denemark sera en mesure de rendre aux chercheurs cet outil de travail aussi inestimable qu'irremplaçable.

43. Le tiers inférieur des folios 45 et 46 a été rogné et restauré avec des morceaux de parchemin. Peut-on supposer l'existence d'une décoration plus sophistiquée à ces endroits ? Peut-être en forme de vignettes semblables aux fol. 14 et 15 décorant les péricopes (voir plus loin)? 
à l'usage de Sens. Le folio $51 v^{0}$ contient Tierce de Sainte Croix et le début de Tierce du Saint-Esprit qui devait probablement se terminer au recto du folio aujourd'hui manquant.

L'heure de Tierce (fol. $\left.52 \mathrm{r}^{\circ}-55 \mathrm{r}^{\circ}\right)$ est amputée de sa page de tête décorée et enluminée (probablement une Annonce aux bergers). Sa structure diffère en plusieurs parties de celle du modèle bisontin : le capitulum Et sic in Syon firmata devrait faire partie de Sexte, alors que son apparition à l'heure de Tierce correspond de nouveau à l'usage de Sens; l'oraison Sancti spiritus quesumus provient de Prime bisontine. Au folio 55 recto et verso apparait l'heure de Tierce de Sainte Croix et du Saint-Esprit.

L'heure de Sexte (fol. $56 \mathrm{r}^{\circ}-58 \mathrm{r}^{\circ}$ ) est de nouveau acéphale (l'enluminure qui manque devait être une Adoration des Mages, ou bien, selon une tradition iconographique bisontine ${ }^{44}$, une rencontre des trois Mages sur le chemin menant à Bethléem) et présente un capitulum irrégulier : le texte à l'incipit Et radicavi in populo correspond encore une fois à l'usage de Sens; il est chanté à l'heure de Tierce selon le modèle bisontin. Les folios $58 \mathrm{v}^{0}$ et $59 \mathrm{r}^{\circ}$ sont occupés par Sexte de Sainte Croix et du Saint-Esprit.

L’heure de None $\left(\right.$ fol. $\left.59 \mathrm{v}^{\circ}-63 \mathrm{r}^{\circ}\right)$ s'ouvre par une page décorée et enluminée, ayant pour thème la Présentation au Temple. Elle présente également quelques variantes textuelles par rapport au canon bisontin et notamment, le capitulum Ego quasi vitis fructificavi qui devrait se trouver à l'heure de Prime. Les oraisons qui concluent l'office de None ne correspondent pas non plus au modèle établi. Ces oraisons sont suivies, au folio 63 recto et verso, par None de Sainte Croix et du Saint-Esprit.

Les Vêpres $\left(\right.$ fol. $\left.64 \mathrm{r}^{\circ}-69 \mathrm{v}^{\circ}\right)$ débutent par une page décorée et enluminée représentant la Fuite en Égypte. Textuellement, elles correspondent entièrement au canon bisontin. Puis, le folio 70 contient les Vêpres de Sainte Croix et du Saint-Esprit.

Les Complies (fol. $71 \mathrm{r}^{\circ}-74 \mathrm{v}^{\circ}$ ) commencent par une page décorée et enluminée représentant le Couronnement de la Vierge. Leur structure textuelle est généralement conforme à l'usage bisontin. Visiblement, la fin est manquante, malgré l'état complet du cahier correspondant (cahier 10). 
L'identification de l'usage du ms. McGill 156 s'est révélée un défi de taille et le verdict définitif n'est pas encore rendu. De façon générale, l'Office de la Vierge semble appartenir à deux traditions. L'usage du diocèse de Besançon y est le plus apparent, renforcé par la présence des dévotions particulières à l'évangéliste Jean, le saint patron de la ville de Besançon, qui s'expriment à travers les oraisons en l'honneur de ce saint à la fin des heures de Matines, Prime, Tierce, Sexte, None et Vêpres de notre manuscrit. L'usage du diocèse de Sens, quant à lui, est repris dans la suite des capituli, à l'exception de None, dont la seule occurrence repérable appartient à l'usage de Chalon-sur-Saône. Le déplacement des Matines de la Croix et du Saint-Esprit vers Laudes est également intéressant.

Peut-on considérer cet Office de la Vierge comme un texte composite, fusionnant ensemble les traditions liturgiques des diocèses voisins pour créer une sorte « d'archive de prière ${ }^{45}$ personnalisée qui refléterait les sensibilités de son commanditaire ? Doit-on plutôt y voir un usage obscur et non répertorié par des savants modernes comme Leroquais et Drigsdah ${ }^{46}$ ? Ou bien, en considérant les leçons fautives du calendrier, y aurait-il lieu d'attribuer les complexités de l'Office de la Vierge du ms. McGill 156 aux compétences d'un scribe mal renseigné au sujet des particularités de la liturgie bisontine?

\subsection{L'Office des morts}

Si l'Office de la Vierge présentait des difficultés d'identification dues à sa structure liturgique, celles observées dans l'Office des morts (fol. $\left.99 \mathrm{r}^{\circ}-136 \mathrm{v}^{\circ}\right)$ sont plutôt d'origine codicologique. En effet, l'ajout d'une nouvelle unité

45. Terme proposé par Virginia Reinburg : "For its owners and readers, the book of hours was an archive because it preserved materials - both written and visual - and ordered them for further use. The book of hours provided its owners and readers with multiple personal scripts for prayer ». Virginia Reinburg, French Books of Hours. Making an Archive of Prayer, c. 1400-1600 (Cambridge : Cambridge University Press, 2012), 5.

46. La base de données Beyond Use cite deux manuscrits contenant quelques leçons semblables à celles du ms. McGill 156. Ce sont les Heures Archiac-Aumont (San Marino, Huntington Library, HM 1137, usage indéterminé) et les Heures Berlaymont (San Marino, Huntington Library, HM 1173, usage indéterminé de l'Office de la Vierge, usage de Besançon pour les litanies et l'Office des morts). Les antiennes de Prime et de None, ainsi que le capitulum de Prime, sont identiques dans les trois manuscrits. Je remercie très sincèrement G. Clark pour ces informations à partir de sa base de données, qui m’ont été fournies au moment où cet article allait sous presse (courriel de 7 juin 2016). 
codicologique correspondant au début du cahier 17 survient juste au milieu de la $\mathrm{VI}^{\mathrm{e}}$ leçon des Matines, au verset 8 du psaume 41. La transition (fol. $122 \mathrm{v}^{\mathrm{0}}-$ $123 \mathrm{r}^{\circ}$ ) parait parfaitement lisse et ne perturbe pas le texte du verset. Néanmoins, le dernier nocturne (les trois dernières leçons) des Matines contenu dans le cahier 17 ne suit plus le modèle liturgique choisi pour le début de l'Office des morts (voir l'Annexe II). En effet, les deux premiers nocturnes (leçons I à VI) correspondent bien au modèle de Besançon tel que relevé par Victor Leroquais ${ }^{47}$. L'interrogation de la base de données Cantus planus élaborée par le professeur Knud Ottosen confirme cette identification ${ }^{48}$. Or, la suite de l'office démontre des irrégularités flagrantes : même si le répons IX des Matines du ms. McGill 156 peut être associé au modèle de Besançon, les répons VII et VIII ne le sont pas $^{49}$. Plus encore, le caractère identique des répons VI et VII («Peccantem me quotidie ») est un non-sens liturgique ${ }^{50}$.

À quel modèle peut bien appartenir le troisième nocturne des Matines? Selon les données de Knud Ottosen, les trois derniers répons correspondent au modèle dominicain ${ }^{51}$. Cependant, si l'on considère le modèle dominicain dans son intégralité ${ }^{52}$, on note une variante dans la leçon IX, «Quare de vulva eduxisti

47. Victor Leroquais, Office des morts. Répons des Matines et antiennes des Laudes, Paris, BnF, NAL 3163, 80.

48. Knud Ottosen, Cantus planus. Responsories of the Latin Office of the Dead, outil de concordance en ligne, consulté le 5 juillet 2015, http://www-app.uni-regensburg.de/Fakultaeten/PKGG/ Musikwissenschaft/Cantus/Ottosen/index.html. Les répons I à VI relevés dans le ms. McGill 156 correspondent aux $\mathrm{n}^{\text {os }} 14,72,24,32,57$ et 68 de la liste alphabétique. La base de données propose treize occurrences bisontines, le reste provenant des manuscrits germaniques ou bien célestins.

49. Selon Victor Leroquais, le modèle bisontin devrait contenir « Redemptor meus vint » pour le répons VII et « Rogamus te Domine » pour le répons VIII. Leroquais, Office des morts, 80.

50. Je tiens à remercier très chaleureusement le professeur Knud Ottosen pour cette précieuse observation, ainsi que pour ses autres remarques et suggestions au sujet de la structure de l'Office des morts du ms. McGill 156.

51. Usage confirmé dans Leroquais, Office des morts, 34. Les répons VII à IX correspondent aux $\mathrm{n}^{\text {os }} 68$, 46 et 38 de la liste alphabétique proposée par la base de données Cantus planus. Parmi les occurrences, la dominante dominicaine est indéniable. Plusieurs autres occurrences renvoient à l'Ouest de la France (Nantes, Saintes), ainsi qu'à l'abbaye bénédictine de Saint-Pierre-aux-Monts dans le diocèse de Châlonssur-Marne. Cependant, ces usages proposent une liste d'antiennes différente pour les Laudes et ne peuvent pas être retenus.

52. Manuscrit cité par Leroquais comme modèle de l'usage dominicain : Heures à l'usage dominicain, dites Heures de Frédéric d'Aragon, Paris, BnF lat. 10532, 251-276 pour les Matines et 276-281 pour 
me " au lieu de "Vir fortissimus » du ms. McGill 156 ; de même, plusieurs versets à la fin des Matines diffèrent de ceux proposés par notre manuscrit.

En ce qui concerne les Laudes, elles reprennent le modèle bisontin relevé par Leroquais ${ }^{53}$, tout en copiant deux fois les antiennes. Ce modèle est très proche de l'usage dominicain, sauf l'antienne IV qui donne "A porta inferi » dans Paris, BnF lat. 10532, tandis que le ms. McGill 156 propose, conformément à l'usage de Besançon, «Eruisti Domine».

Considéré dans son ensemble, l'Office des morts du ms. McGill 156 ne correspond à aucun usage connu. Comparé aux autres éléments textuels déjà analysés, il ne contient aucune ressemblance avec les usages des diocèses comme Troyes, Langres ou Sens. Prenant en compte le changement d'unités codicologiques, notons une volonté apparente de compléter le texte liturgique, peut-être à partir d'éléments disponibles dans l'atelier sans pour autant chercher à faire converger les répons vers un usage régional précis. Ceci étant dit, la recherche de conformité au modèle bisontin paraît assez évidente et, sur la foi des six premières leçons, doit être avancée comme un élément d'identification majeur.

\section{Le programme artistique}

Du point de vue artistique, le ms. McGill 156 offre un programme décoratif varié et intéressant qui répond aux objectifs formels et esthétiques du genre. Malgré son état composite, lacunaire et détérioré, nous pouvons reconstruire sa structure visuelle qui sert à faciliter la lecture tout en mettant en valeur certains éléments textuels.

La partie la plus sobre du manuscrit est certainement le calendrier dont la décoration reste purement fonctionnelle et traditionnelle avec les initiales champies KL et une mise en vedette de certaines fêtes à l'aide de l'encre rouge. Les péricopes des Évangiles offrent une décoration marginale à la fois sobre et recherchée : bordures fleuries sur trois marges, initiales champies sur deux lignes pour le début de chaque évangile ; les fines baguettes en or séparent le texte et la bordure de gauche. La bordure inférieure reçoit des médaillons avec

les Laudes. Facsimilé digital intégral consultable sur Gallica. 7 novembre 2011, http://gallica.bnf.fr/ ark:/12148/btv1b8427228j.

53. Leroquais, Office des morts, 80 . 
les portraits simples et traditionnels des évangélistes Jean sur l'île de Patmos et Luc (fol. $14 \mathrm{r}^{\circ}$ et $15 \mathrm{r}^{\circ}$ ). Les parties inférieures des folios 16 et 17 , contenant respectivement les évangiles de Matthieu et de Marc, ont été endommagées et restaurées : elles offraient probablement les portraits de ces évangélistes.

Le « cœur liturgique » du ms. McGill 156 (les Heures de la Vierge, les Psaumes, ainsi que l'Office des morts) est également la seule partie du manuscrit qui jouit d'un programme iconographique complet. On y voit des miniatures, mais également une mise en forme visuelle importante des éléments textuels essentiels : bordures, lettrines, initiales peintes bicolores de dimensions diverses, rubriques à l'encre rouge, tous les éléments du décor contribuant à créer une structuration hiérarchique et modulaire du texte. Certains éléments, comme les Matines de la Croix et du Saint-Esprit, reçoivent une attention particulière à l'aide d'une bordure fleurie sur trois marges, dont l'ampleur ne peut pas être appréciée aujourd'hui à cause de l'état mutilé de ces folios. La prière Obsecro te se démarque des oraisons qui la précèdent par la riche décoration marginale et par la grande initiale $O$ historiée représentant la Vierge et l'Enfant.

Les cahiers 17-22 rajoutés au manuscrit, accusent une qualité moins soignée dans l'exécution des petites initiales bicolores. Cependant, c'est là que se trouve le segment le plus décoré du manuscrit, grâce à l'abondance de la décoration marginale et l'exécution particulièrement riche des grandes initiales, mettant en valeur les suffrages, les prières mariales, les Huit vers de saint Bernard. En fait, chaque oraison est marquée d'une bordure décorée et d'une grande initiale, ce qui représente une suite de vingt-deux folios décorés ! Ce programme décoratif cherche à s'inscrire dans le projet artistique des cahiers 3-16, avec cependant des limites qui seront examinées plus loin.

Le décor du manuscrit McGill 156 est complété à l'origine par dix miniatures dont trois ont depuis été perdues. Les sept enluminures conservées, toutes de demi-page, sont polychromes et rehaussées d'or et représentent l'Annonciation, la Nativité, la Présentation au Temple, la Fuite en Égypte, le Couronnement de la Vierge, David en prière et une Messe funéraire.

L'analyse des bordures et des miniatures aux fins d'attribution artistique de ce manuscrit présente plusieurs difficultés d'ordre matériel, liées aux mutilations subies par ce manuscrit, ainsi qu'à l'état médiocre de la conservation des pigments. L'examen général du décor permet de constater, dès le premier abord, l'intervention de plusieurs artistes, car les bordures des cahiers 3-16 ne sont certainement pas dues au même enlumineur que celles des cahiers 17-22 ; 
quant aux miniatures, aux médaillons et à l'initiale historiée $\mathrm{O}$ de l'Obsecro te, les questions soulevées par les particularités stylistiques de ces éléments iconographiques méritent une analyse plus détaillée. Pour le moment, notons le profond contraste entre leur qualité d'exécution et l'art raffiné de la bordure des cahiers 3-16.

L'état de conservation du manuscrit a nécessité une évaluation technique plus poussée, dont un examen au microscope des images et de certaines initiales ${ }^{54}$. Cet examen a permis de constater plusieurs grattages et pertes picturales, surtout dans le médaillon au fol. $14 \mathrm{r}^{\circ}$ et les initiales du cahier 19, fol. 137-144, attribuables peut-être à la volonté de recycler les pigments. L'agrandissement a démontré l'état détérioré des visages et des mains des personnages, les pigments rose et chair partiellement disparus laissant à découvert le gesso gris. Par ailleurs, la dorure à l'encre d'or et les contours grisnoir paraissent homogènes dans l'ensemble des images analysées ${ }^{55}$, tout comme la gamme des pigments utilisés. Aucune superposition de couches picturales n’a été relevée ; au contraire, certaines images contiennent des endroits non peints laissant transparaître le parchemin, sans doute en raison des maladresses apparentes dans l'exécution des miniatures. L'analyse visuelle détaillée a enfin permis de formuler deux observations essentielles pour l'évaluation du manuscrit : en ce qui concerne l'attribution, l'exécution des bordures et des images des cahiers 3-16 ne peut pas être attribuée au même artiste ; quant à la datation, aucun indice ne permet d'affirmer l'existence de retouches ni d'ajouts modernes attribuables à une restauration qui serait postérieure à l'époque de datation du contenu textuel du manuscrit.

Peut-on aller plus loin dans l'attribution et la datation du décor du ms. McGill 156 ? Outre les observations d'ordre technique, toute analyse iconographique doit également prendre en compte les problèmes d'identification textuelle et cultuelle déjà traités dans le présent article. Dans sa notice descriptive, L. Wysocki proposait d'identifier le peintre du ms.

54. Je remercie le Musée des Beaux-arts de Montréal pour avoir rendu possible cette évaluation et plus particulièrement Mme Johanne Perron, restauratrice, pour ses conseils et observations. De même, tous mes remerciements à Mme Doris St-Jacques, conservatrice, Bibliothèque et Archives Canada, pour sa magnifique classe de maître sur l'exemple d'un graduel manuscrit italien fortement retouché.

55. Notamment, on a constaté que certaines taches de pigments avaient disparu avec les éléments de contours et de dorure correspondants. 
McGill 156 aux cercles familiers avec le style de Guillaume Vrelant ${ }^{56}$. Toutefois, l'examen attentif du corpus iconographique attribué à cet enlumineur brugeois actif dans le troisième quart du $\mathrm{XV}^{\mathrm{e}}$ siècle, ainsi qu'à son cercle ${ }^{57}$, n'a pas permis de constater des similitudes stylistiques ou morphologiques significatives. Cette hypothèse doit donc être écartée.

Les affinités géographiques du ms. McGill 156 amènent naturellement à l'examen des œuvres effectuées par des artistes appartenant à la fois à l'espace bisontin et aux centres de production artistique géographiquement rapprochés, dont les plus importants se situaient à Troyes (Champagne), à Besançon (Franche-Comté) et à Dijon (Bourgogne, diocèse de Langres). Des éléments iconographiques - notamment, la composition des scènes de la Présentation au Temple et de David en prière - l'associent à une tradition propre à l'iconographie bisontine, telle que relevée par François Avril, Vera Vines, de même que Gregory Clark ${ }^{58}$. Cependant, certaines particularités du style iconographique - le traitement des bordures, la composition et la palette de certaines scènes, le style de certains éléments décoratifs (arbres, motifs architecturaux, draps d'honneur) - font penser plus spécifiquement à l'atelier de l'enlumineur connu sous le titre du Maître du Missel de Troyes ${ }^{59}$.

Le Maitre du Missel de Troyes fut actif dans le troisième quart du XV $\mathrm{XV}^{\mathrm{e}}$ siècle, exécutant des commandes artistiques pour les élites aristocratiques, ecclésiastiques et bourgeoises des régions de la Champagne et de la FrancheComté. Son atelier se situait probablement d'abord à Troyes et plus tard, à

56. Wysocki, 1, « Manuscript written and decorated [...] by people familiar with Willem Vrelant's work ».

57. Par exemple, les Heures Arenberg, Los Angeles, The J. Paul Getty Museum, ms. Ludwig IX 8 ; Baltimore, Walters ms. W.177, W.179, W.183... Pour une étude d'ensemble de l'activité de Guillaume Vrelant, voir la monographie très détaillée de Bernard Bousmanne, "Item a Guillaume Wyelant aussi enlumineur ": Willem Vrelant. Un aspect de l'enluminure dans les Pays-Bas méridionaux sous le mécénat des ducs de Bourgogne Philippe le Bon et Charles le Téméraire (Turnhout : Brepols, 1997). On y trouve l'examen minutieux des techniques et des trouvailles stylistiques de Vrelant, ainsi qu'une multitude d'exemples dont aucun ne permet de faire de rapprochement avec l'iconographie du manuscrit McGill 156.

58. François Avril et Nicole Reynaud, Manuscrits à peintures en France, 1440-1520 (Paris : Flammarion, 1993), 180-181 ; Vines, «A Centre for Devotional and Liturgical Manuscript Illumination », 195-209; Gregory Clark et collectif, «Les manuscrits à peintures au Moyen Âge : bilan et perspectives de la recherche ", Perspective 2 (2010) :309-310.

59. Je tiens à remercier très chaleureusement $\mathrm{M}$. Gregory Clark pour ses précieuses suggestions. 
Besançon, ce qui explique son second sobriquet adopté par la critique moderne, celui du « Maître de Charles de Neuchâtel ». Relativement peu étudié, il a néanmoins suscité l'attention des savants comme François Avril ${ }^{60}$. Enfin, Jacques Lauga lui consacre un chapitre dans sa thèse sur les manuscrits liturgiques du diocèse de Langres ${ }^{61}$, dans lequel il dresse une liste des manuscrits, pour la plupart des livres liturgiques à l'usage de Troyes, de Langres et de Besançon, attribuables à ce maître enlumineur ${ }^{62}$. Ainsi, sa clientèle connue correspond généralement à la localisation géographique des parties liturgique et cultuelle du ms. McGill 156 ${ }^{63}$. Parmi ces manuscrits (dont la plupart sont aujourd'hui accessibles en format numérique, ce qui facilite grandement l'analyse comparée), on trouve de nombreuses similitudes frappantes avec la décoration primaire et secondaire du ms. McGill 156. C'est, avant tout, le Missel de Troyes (Paris, BnF lat. $\left.865 \mathrm{~A}^{64}\right)$, copié par le scribe Jean Coquet vers 1460 , qui constitue la référence principale à l'art de ce maître ; signalons aussi le ms. 112 de la Bibliothèque municipale de Marseille ${ }^{65}$, un livre d'Heures à l'usage de Troyes (Troyes, Bibliothèque municipale, ms. 389766), les Heures Habert du Berry d'Artois-Hoe à l'usage de Troyes (Cambridge, Houghton Library, ms. Richardson $7^{67}$ ), les

60. Avril et Reynaud, Manuscrits à peintures, 181-184 ; également, "Le Maître du Missel de Troyes », in Très riches heures de Champagne, éd. François Avril, Maxence Hermant et Françoise Bibolet (Paris : Hazan, 2007), 43, 50 et 126-137.

61. Lauga, $1: 201-215$. Mes sincères remerciements à M. Lauga pour le prêt généreux de sa thèse et pour ses aimables communications.

62. Lauga, $1: 201-202$ et $3: 39-40$.

63. Voir la carte démontrant la répartition des commandes dans Lauga, $3: 231$.

64. Numérisation intégrale sur Gallica, site consulté le 25 mai 2015. http://gallica.bnf.fr/ark:/12148/ btv1b7200001s/f1.planchecontact.r=Bnf\%20latin\%20865a.

65. Images consultables dans la Bibliothèque virtuelle des manuscrits médiévaux, accédé le 24 octobre 2015, http://bvmm.irht.cnrs.fr/consult/consult.php?reproductionId=7219.

66. Voir la description du manuscrit ainsi qu'une sélection de ses pages au http://www.mediatheque. grand-troyes.fr/webmat2/archives/_/feuilletoir/Ms3897.html (site consulté le 25 octobre 2015). Je remercie la Médiathèque du Grand Troyes et plus particulièrement M. Pascal Jacquinot pour m’avoir donné l'accès à la copie numérique intégrale de ce manuscrit.

67. Heures à l'usage de Troyes, datées vers 1470. Voir Roger S. Wieck, Late Medieval and Renaissance Illuminated Manuscripts (1350-1525) in the Houghton Library (Cambridge : Harvard College Library, 1983), 28-29 ; Lauga, $1:$ 201-205. Le facsimilé digital peut être consulté au http://pds.lib.harvard.edu/ pds/view/5981093 (site consulté le 15 mai 2015). Wieck, suivant les notes de Leroquais, identifiait l'usage de l'Office de la Vierge comme celui de Sens. Il s'agit, en fait, de l'usage de Troyes (Victor Leroquais, 
Heures à l'usage de Rome (Cambridge, Houghton Library, ms. Typ. 21), les petites miniatures des Heures Carruel à l'usage de Langres ${ }^{68}$. Quant au Missel de Saint-Jean-au-Marché (Troyes, Bibliothèque municipale, ms. 117), cette copie postérieure et «d'une toute autre main ${ }^{69}$ que le Missel de Troyes démontre, malgré son programme décoratif beaucoup plus réduit ${ }^{70}$, le même engouement pour les bordures et les modèles iconographiques élaborés par le maître. Cependant, la proximité la plus flagrante se manifeste entre le ms. McGill 156 et les Heures dites Lardanchet ${ }^{71}$ : exécutées aux alentours des années 1460, elles présentent non seulement un programme iconographique similaire à celui du ms. McGill 156, mais également le même caractère géographique composite aux affinités franc-comtoises, jurassiennes et champenoises ${ }^{72}$.

S'inspirant largement des modèles parisiens des années 1420 , et notamment ceux proposés par le Maître de Bedford, le Maître du Missel de Troyes se démarque par « le traitement plus timide de l'espace, du paysage et de l'architecture $»^{73}$ que ses prédécesseurs parisiens. En même temps, il fait partie de ces enlumineurs français inspirés par les trouvailles artistiques des peintres flamands dont il imite la recherche de l'espace profond et l'atmosphère lumineuse $\mathrm{e}^{74}$. Par ailleurs, plusieurs manuscrits de grand luxe attribués à sa période troyenne partagent le même traitement stylistique de la bordure. Certains d'entre eux - notamment, les Heures Habert du Berry d'Artois-Hoe

L’Office de la Vierge, Paris, BnF, nouv. acq. lat. 3162, fol. 194), comme le démontre Eric Drigsdahl dans les notes au modèle de l'usage de Sens.

68. Eberhard König, Tour de France. 32 Manusckripte aus den Regionen Frankreichs ohne Paris und die Normandie 13 bis 16 Jahrhundert, 2 vol. (Ramsen : Heribert Tenschert, 2013), 1 :235-264.

69. Avril, Très riches heures de Champagne, 126 et les reproductions des enluminures aux fig. 122 et 113.

70. Le manuscrit 117 de la B. m. Troyes ne contient que deux enluminures de pleine page, la Crucifixion (fol. $143 \mathrm{v}^{\circ}$, copie du BnF lat. 865A, p. 418) et Dieu en majesté (fol. 144ro , copie du BnF lat. 865A, p. 419). 71. http://www.medievalbooksofhours.com/inventory/boh_114, site consulté le 10 juillet 2015. La notice du manuscrit a été élaborée par les soins d'Ariane Bergeron-Foote.

72. Leur Office de la Vierge est à l'usage de Paris, l'Office des morts est écourté et ne peut pas être localisé, les éléments hagiographiques pointent vers la Franche-Comté, le Jura et la Champagne. Voir la notice d'Ariane Bergeron-Foote.

73. Avril et Reynaud, Manuscrits à peintures, 182.

74. Avril, Très riches heures de Champagne, 126. 
et les Heures de Troyes ms. $3897^{75}$ - déploient une véritable hiérarchie de la décoration marginale. Ainsi, les pages contenant les miniatures s'accompagnent de bordures de quatre marges ( «style A »), densément semées de tiges de fines acanthes frisées bicolores et de tiges fleuries, dont la palette associe les verts délavés des feuilles aux couleurs pastel des petites fleurs peintes au naturel. Les pages non-enluminées sont ornées de bordures sur trois ou quatre marges ( «style $\mathrm{B}$ ») composées de fins rinceaux à l'encre noire aux vrilles et aux feuilles de lierre trilobées en or, de "bouquets " fins d'acanthes frisées et de tiges fleuries aux extrémités de la bordure, entremêlant les fleurs peintes au naturel et les fleurs quadrilobées stylisées ; un fin cadre champi sépare la bordure du texte. Des petites créatures, le plus souvent des oiseaux, peints de profil avec un naturalisme étonnant, viennent égayer ces marges décorées ${ }^{76}$. Les manuscrits moins luxueux, dont le Missel de Troyes, le Missel de Saint-Jean-au-Marché, adoptent ce style plus aéré pour leurs pages enluminées.

Vers la fin de sa vie, notre maître enlumineur aurait été établi à Besançon, exécutant notamment un livre d'Heures aujourd'hui conservé à New York, Pierpont Morgan Library, ms. M $28^{77}$, un pontifical commandé par Charles de Neuchâtel, évêque de Besançon (Besançon, Bibliothèque municipale, ms. 115$117^{78}$ ), un missel exécuté pour ce même patron (Auckland, Auckland City Librairies, Special Collections, Med. MSS G. 138-139), ainsi qu'un pontifical fait pour son neveu Antoine de Neuchâtel (Besançon, Bibliothèque municipale, ms. $157^{79}$ ). À cette liste devraient peut-être s'ajouter plusieurs livres d'Heures

75. Les images mentionnées pour les manuscrits de comparaison peuvent être consultées à partir des fac-similés digitaux cités plus haut. Les images des Heures Lardanchet sont reproduites dans le corps du présent article.

76. Les Heures Habert du Berry d'Artois-Hoe offrent une plus grande variété de la faune marginale : à part les oiseaux, des petits animaux ainsi que des grotesques.

77. Images consultables sur le site CORSAIR de la Pierpont Morgan Library \& Museum, http://corsair. themorgan.org/cgi-bin/Pwebrecon.cgi?BBID=76870 (site consulté le 25 octobre 2015).

78. Site consulté le 25 octobre 2015, http://bvmm.irht.cnrs.fr/consult/consult.php?reproductionId=7705, http://bvmm.irht.cnrs.fr/consult/consult.php?reproductionId=7706, http://bvmm.irht.cnrs.fr/consult/ consult.php?reproductionId=7707.

79. Site consulté le 25 octobre 2015, http://bvmm.irht.cnrs.fr/consult/consult.php?reproductionId=7733. Les manuscrits issus de la période d'activité « bisontine " de notre enlumineur présentent moins de ressemblances avec le style pictural du manuscrit McGill 156, tant dans sa décoration secondaire que dans la composition et l'exécution des enluminures. Afin de ne pas alourdir l'analyse comparée, ce corpus sera moins sollicité. 
à l'usage de Besançon, notamment les Heures de Besançon, Bibliothèque municipale, ms. $125^{80}$.

\subsection{La décoration secondaire du ms. McGill 156 : les bordures}

Comme il a été observé plus haut, les bordures du ms. McGill 156 furent exécutées par deux artistes : le premier est responsable des cahiers 3-16 et le second - des cahiers 17-22. Or, les marges des pages enluminées des cahiers 3-16 du ms. McGill 156 reproduisent de façon littérale le «style B » propre aux manuscrits de la période «troyenne » du Maître de Missel de Troyes (voir fig. 1 et 9). Elles en partagent également l'exceptionnelle qualité d'exécution ${ }^{81}$. Les fines tiges aux feuilles génériques mêlant l'or et le vert pâle, sont surmontées par des touffes de fleurs des champs comme la véronique, la pâquerette, le rosier, la giroflée, le fusain, la bourrache, la centaurée, le perce-neige, mais aussi des fruits comme les fraises. Les fruits d'aubépine alternent avec des tiges de fines acanthes frisées bicolores qui parfois prolongent le cadre champi de la miniature. Les petites feuilles de lierre en feuille d'or sont entremêlées de vrilles et de fleurs solitaires.

Quant à l'enlumineur responsable de la décoration des cinq derniers cahiers du manuscrit McGill 156, il imite ce style, avec toutefois quelques nuances notables : les tiges feuillues deviennent plus épaisses, on observe une plus grande variété dans la forme des feuilles ; les fleurs sont de dimension plus importante et d'exécution généralement moins soignée; on note l'absence des acanthes dans plusieurs bordures (fol. $150 \mathrm{v}^{\circ}, 151 \mathrm{r}^{\circ}, 152 \mathrm{v}^{\circ}$ ), tandis quailleurs elles s'intègrent aux tiges florales ou aux extrémités du cadre intérieur de la bordure qui s'orne de pommeaux colorés assez proéminents. Le deuxième artiste emploie des pigments bleus différents de ceux des cahiers 3-16 ; l'exécution des grandes initiales ornées est moins raffinée, malgré l'emploi plus prononcé de la feuille d'or. En général, les bordures des cinq derniers cahiers ne démontrent pas la même maîtrise des proportions et de l'harmonie picturale que la première partie du manuscrit. Certaines initiales sont plus riches que les autres, notamment celles qui accompagnent les oraisons aux saints Fiacre,

80. Images consultables sur le site de la Bibliothèque virtuelle des manuscrits médiévaux : http://bvmm. irht.cnrs.fr/consult/consult.php?reproductionId=7712 (site consulté le 25 octobre 2015).

81. Contrairement, par exemple, aux Heures Lardanchet dont l'art marginal est nettement moins raffiné. 


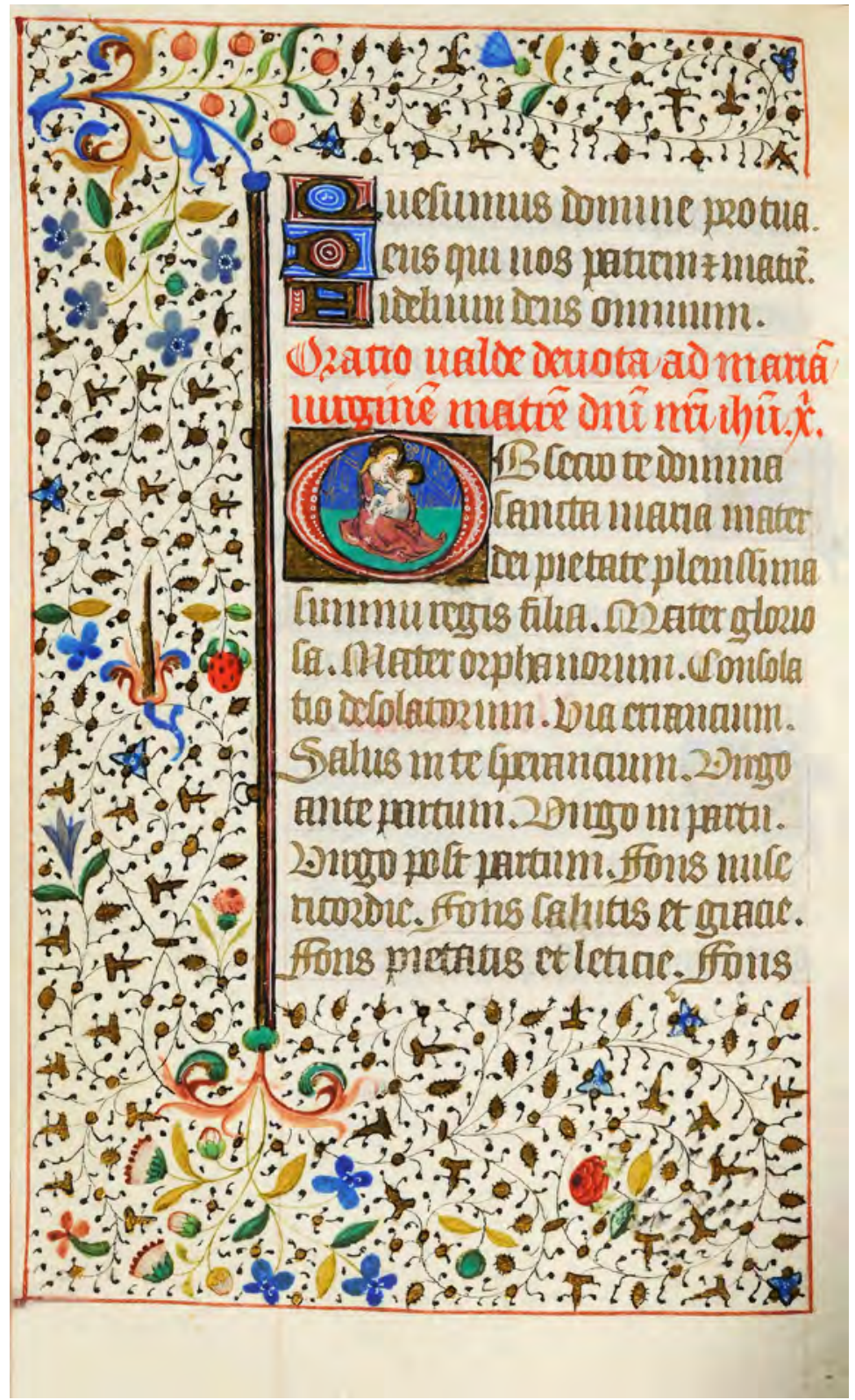

Fig. 1. Horae, Obsecro te. Bordure florale et initiale historiée. Montréal, McGill, LRCS, MS 156, fol. $95 v^{\circ}$. 


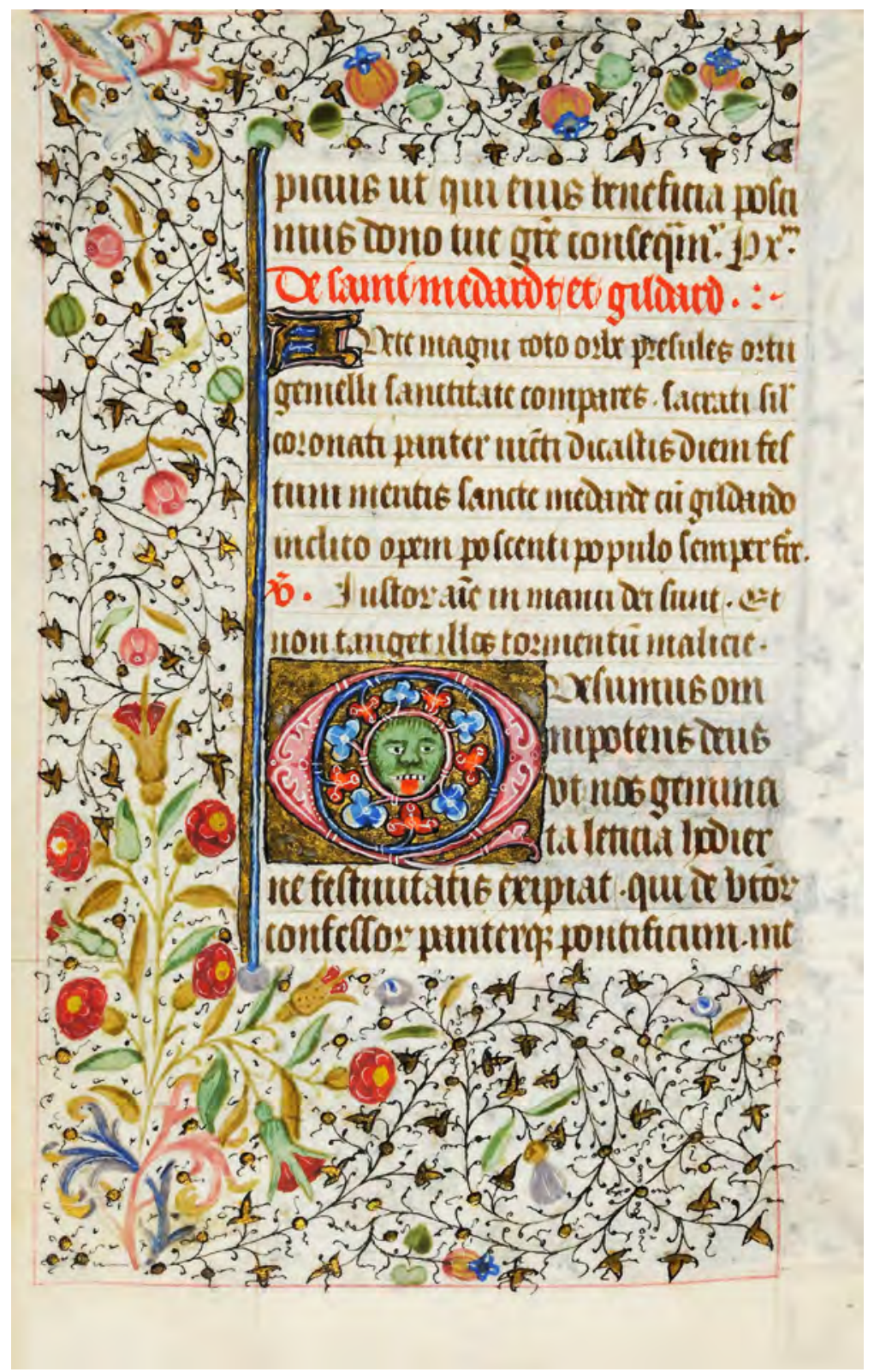

Fig. 2. Horae, Suffrages à Médard et Gildard. Bordure florale et initiale habitée. Montréal, McGill, LRCS, MS 156, fol. 156vº 
Bénigne, Adrien ; l'oraison à Médard et Gildard est marquée par une grande initiale ornée d'un motif zoomorphe (une tête de monstre de couleur verte, voir fig. 2), ce qui est une exclusivité dans ce manuscrit. La longue série de bordures décorées, la fréquence des grandes initiales au fond en feuille d'or contribuent à la mise en valeur spectaculaire de ce dernier segment du manuscrit, créant un sentiment d'unité entre le corps des suffrages et les trois " suffrages supplémentaires » - un argument important en faveur de l'unité codicologique des cahiers 17-22.

\subsection{Le programme iconographique du ms. McGill 156 : les vignettes}

Les images du manuscrit McGill 156 s'inspirent assez nettement du style du Maître du Missel de Troyes, sinon dans la finesse de l'exécution, du moins dans leur composition. Très souvent, elles y empruntent également la palette de couleurs. Ceci est apparent avant tout dans les petites vignettes (médaillons marginaux et une initiale historiée) de notre manuscrit. Ainsi, le portrait de l'Évangéliste Luc (fol. $15 \mathrm{r}^{\circ}$ ) et la Vierge à l'Enfant (fol. $95 \mathrm{v}^{\circ}$, fig. 1) peuvent être directement associés aux initiales historiées du manuscrit Cambridge, Houghton, Typ. $21^{82}$. Les similitudes sont encore plus frappantes dans le cas du portrait de Jean l'Évangéliste dans la marge inférieure du fol. 14r comparé à celui des Heures Lardanchet ${ }^{83}$ : la position de l'écrivant, l'inclination vers le bas de sa tête aux cheveux dorés, la position du livre sur le genou gauche du personnage, la position de l'aigle, et le paysage accidenté qui l'entoure démontrent avec certitude l'emploi du même modèle pour la composition de l'image (voir fig. 3 et 4). Les Heures Habert du Berry d'Artois-Hoe (p. 25) et celles de Marseille B. m. 112 (fol. 3) reproduisent le même modèle de composition avec quelques légères modifications. Dans le cas des Heures Habert du Berry d'Artois-Hoe, la scène devient beaucoup plus détaillée ; on note l'introduction de l'ange bénisseur habillé de blanc qui semble plonger du ciel - cet ange est un personnage récurrent dans les enluminures du manuscrit.

La qualité de l'exécution, cependant, démontre toute la complexité de la filiation iconographique entre tous ces manuscrits et le ms. McGill 156. Entre

82. Voir les reproductions des images, http://nrs.harvard.edu/urn-3:FHCL.HOUGH:753812 (site consulté le 25 octobre 2015) - Luc au fol. $15 v^{\circ}$ et la Vierge et l'Enfant au fol. 169v $v^{\circ}$.

83. Je remercie Ariane Bergeron-Foote pour m'avoir gracieusement communiqué la notice complète de ce manuscrit, ainsi que les images reproduites dans le présent article. 
autres, on y observe le caractère simplifié du paysage, la substitution de l'arrièreplan et de l'emplacement aquatique de l'île par un fond bleu-clair uniforme très saturé ; la recherche de profondeur s'accomplit par l'usage d'un contour noir et par les accents dorés aux traits épais et peu soignés, surtout dans le fond. L'état détérioré de l'enluminure - la perte presque intégrale de la couche picturale représentant l'île, les pertes importantes au niveau du visage du personnage et du corps de l'oiseau - contribue à souligner l'écart important dans la qualité d'exécution entre le ms. McGill 156 et les autres manuscrits contemporains attribués au Maître du Missel de Troyes. Le même phénomène est observable pour l'ensemble du programme iconographique de notre manuscrit.

\subsection{Le programme iconographique du ms. McGill 156 : les miniatures}

Parmi les sept enluminures de demi-page présentement conservées dans le manuscrit, les scènes représentant l'Annonciation, la Présentation au Temple, le Couronnement de la Vierge et David en prière semblent être très proches des modèles observés dans les manuscrits attribués à l'atelier du maître du Missel de Troyes de la période troyenne. Une exception notable concerne quelques visages masculins, comme celui de David dans la miniature qui précède les psaumes pénitentiaux, dont certains traits peuvent être rapprochés du style pictural propre au maître de Michel Jouvenel des Ursins, un autre enlumineur actif dans la même région et collaborateur du maître du Missel de Troyes pour les images des Heures Carruel ${ }^{84}$. Quant aux images qui représentent la Nativité et la Fuite en Égypte, elles gardent les caractéristiques iconographiques essentielles propres au style du maitre du Missel de Troyes sans pour autant les reproduire avec autant de netteté. En ce qui concerne l'image de la Messe funéraire, elle se démarque de façon décisive des modèles utilisés dans les manuscrits du corpus même pris au sens le plus large.

84. Voir notamment König, Tour de France, $1: 235-264$. Les autres manuscrits attribués à ce maître incluent les Heures de Michel Jouvenel des Ursins, Paris, BnF, NAL 3113 en numérisation intégrale sur Gallica (http://gallica.bnf.fr/ark:/12148/btv1b60005168) et les Heures à l'usage de Metz, vente Christie's $n^{\circ} 10455,15$ juillet 2015. Je remercie très chaleureusement Gregory Clark pour ses suggestions concernant le rapprochement entre l'art de cet enlumineur et l'iconographie du ms. McGill 156. 


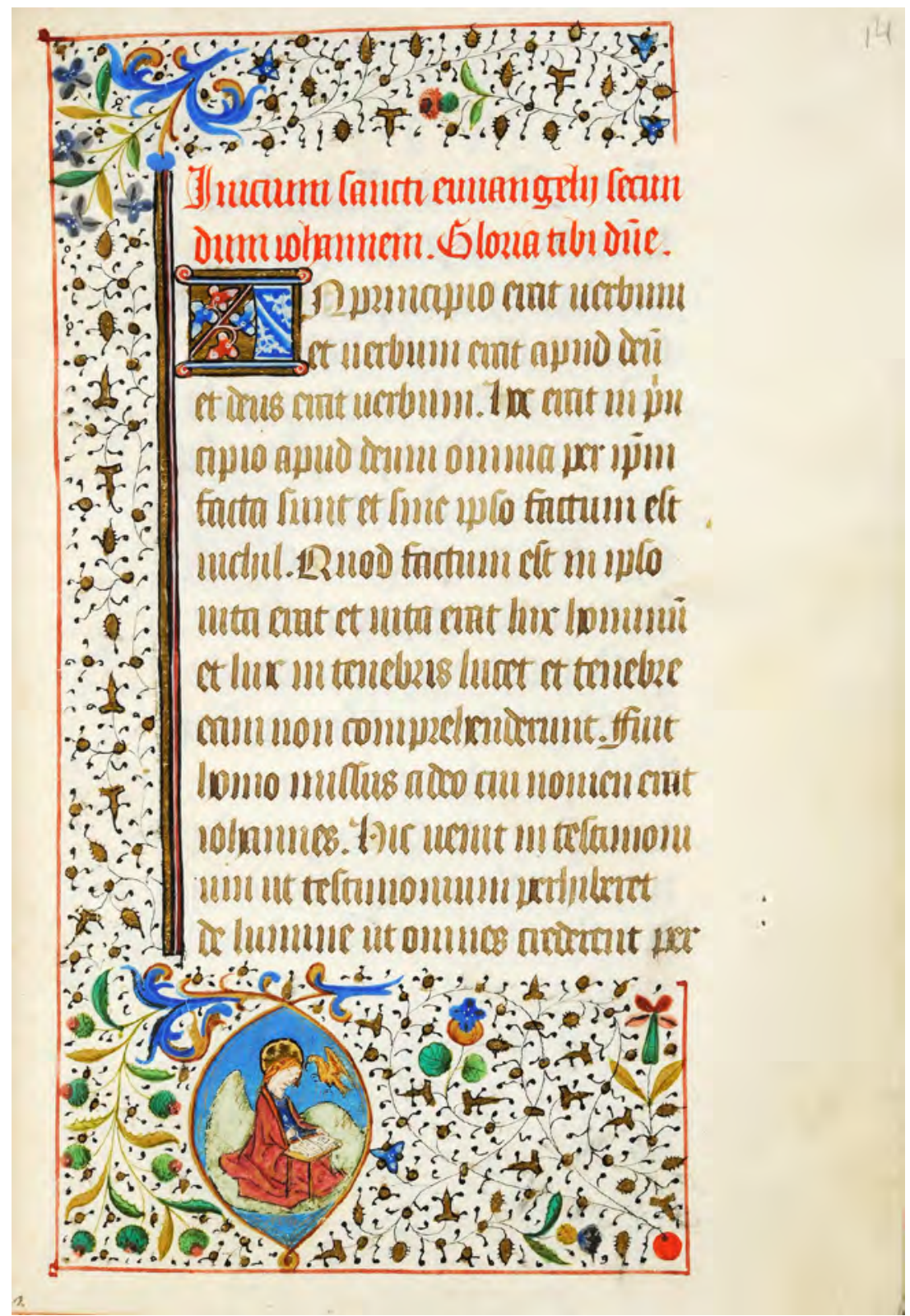

Fig. 3. Horae, Péricope de Jean, saint Jean à Patmos. Montréal, McGill, LRCS, MS 156, fol. $14 \mathrm{r}^{\circ}$. 


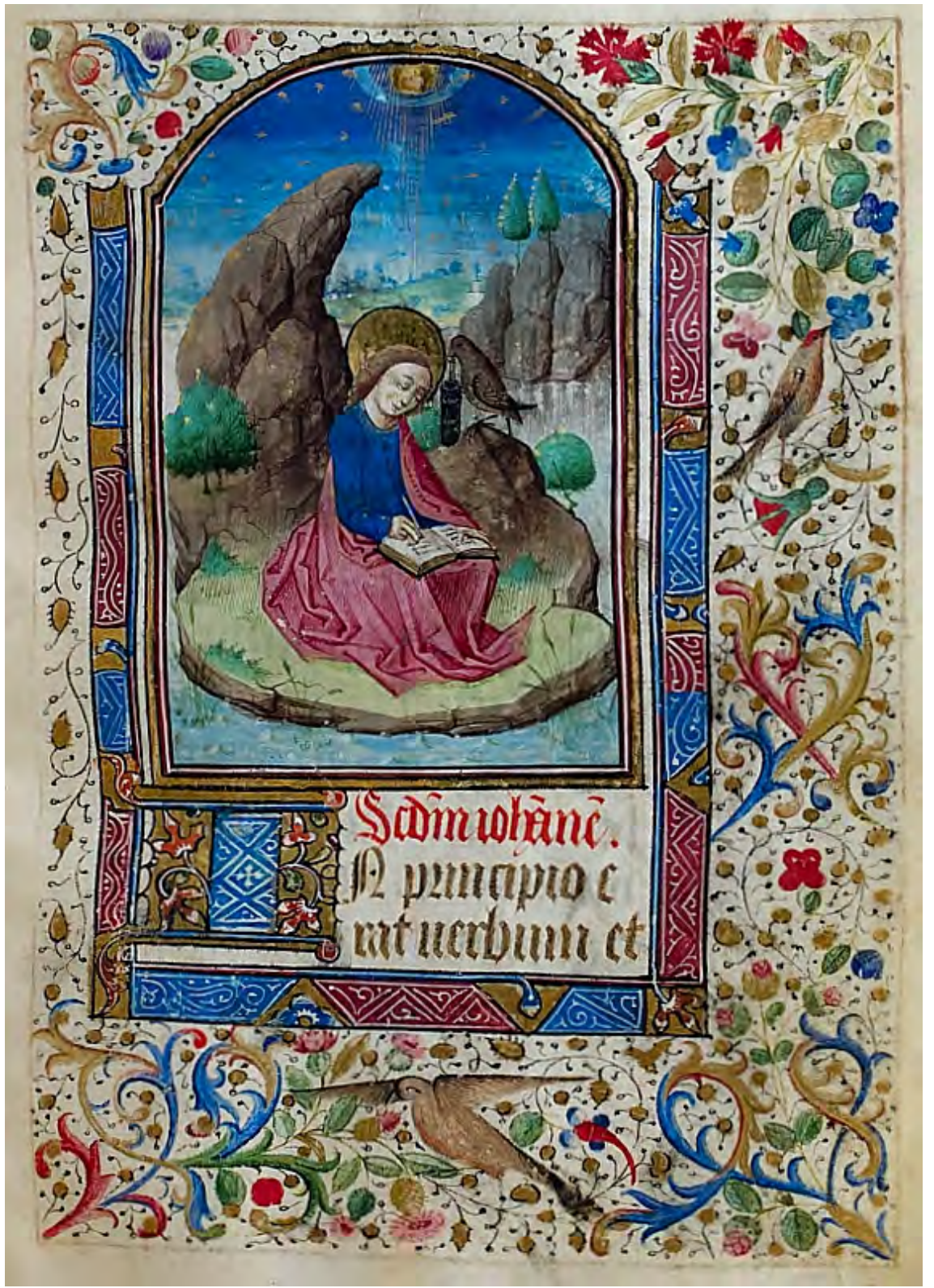

Fig. 4. Heures Lardanchet, saint Jean à Patmos. Paris, Galerie Les Enluminures, BOH 114, fol. 14r ${ }^{\circ}$. CLes Enluminures. 


\subsubsection{L'Annonciation}

La scène del'Annonciation du ms. McGill 156 (fol. 22r r $^{\circ}$, fig. 5) est stylistiquement très proche de celle des Heures Lardanchet (fol. $28 \mathrm{r}^{\circ}$, fig. 6) et, dans une moindre mesure, de celle du Missel de Troyes (p. 483) et des Heures Habert du Berry d'Artois-Hoe (p. 93). L'ange Gabriel, vêtu d'un habit blanc à capuche rappelant celui des moines cisterciens, tient dans sa main gauche un phylactère sinueux avec la salutation angélique qu'il pointe d'un doigt de sa main droite. Son attitude révérencieuse se prolonge dans la rotation du corps de Marie dans ces trois manuscrits ; cependant, l'artiste du ms. McGill 156 place Marie - dont les traits et les accessoires, y compris le coussin placé sous les genoux, paraissent directement empruntés au Missel de Troyes - face à son interlocuteur, une attitude à la fois plus franche et plus résignée. Un drap d'honneur - une large tenture rouge damassée d'or - remplit la fonction de mise en exergue de l'action, séparant l'avant-scène de l'arrière-plan architectural constitué par une arcade de fenêtres et une grande ouverture à gauche où apparaît Dieu bénissant, source des rayons de lumière dorée. La présence de tels draps d'honneur dans les scènes d'intérieur constitue l'une des marques distinctives du style du Maître du Missel de Troyes. Le carrelage vert du plancher, le baldaquin au fond de l'espace quasi-ecclésial soulignent la solitude de Marie. Notons la présence d'un deuxième livre ouvert posé derrière Marie, proposant un double contexte de la dévotion et de l'étude.

Comparée à celles des autres manuscrits de notre échantillon, l'exécution artistique de la scène dans le ms. McGill 156 affiche plusieurs simplifications significatives : le plancher, le baldaquin, la table couverte d'un tissu blanc transparent ne respectent pas les lois de la perspective ; le ciel dans l'ouverture à gauche de l'image est uniforme, sans effet de dégradé ; les couches picturales, surtout le vert, le bleu céleste et le blanc de la robe de l'ange, manquent de finesse et de transparence caractéristiques de l'art du Maître du Missel de Troyes. Le contour noir et les accents dorés aux traits épais sont omniprésents. 


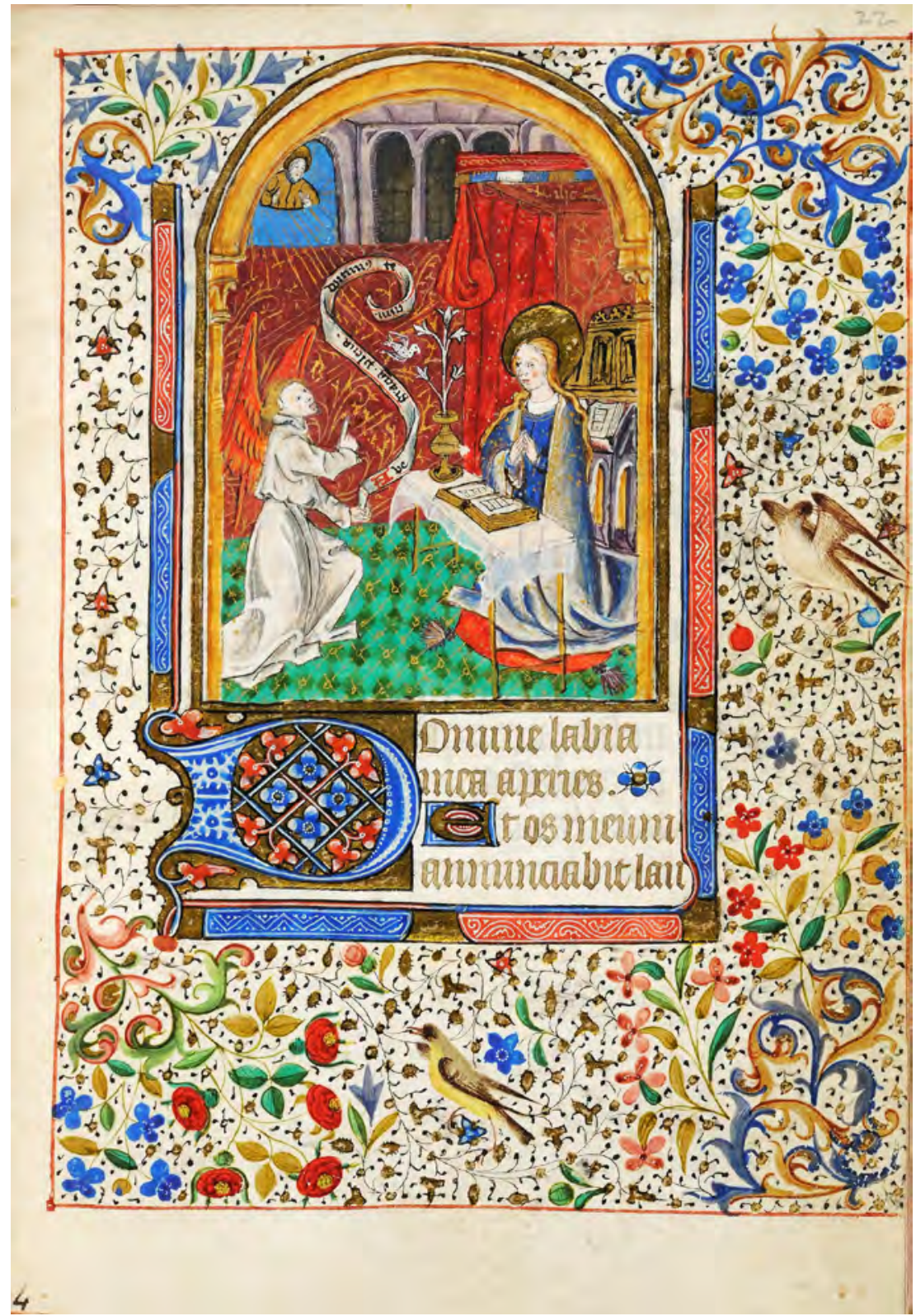

Fig. 5. Horae, l’Annonciation. Montréal, McGill, LRCS, MS 156, fol. $22 r^{\circ}$. 


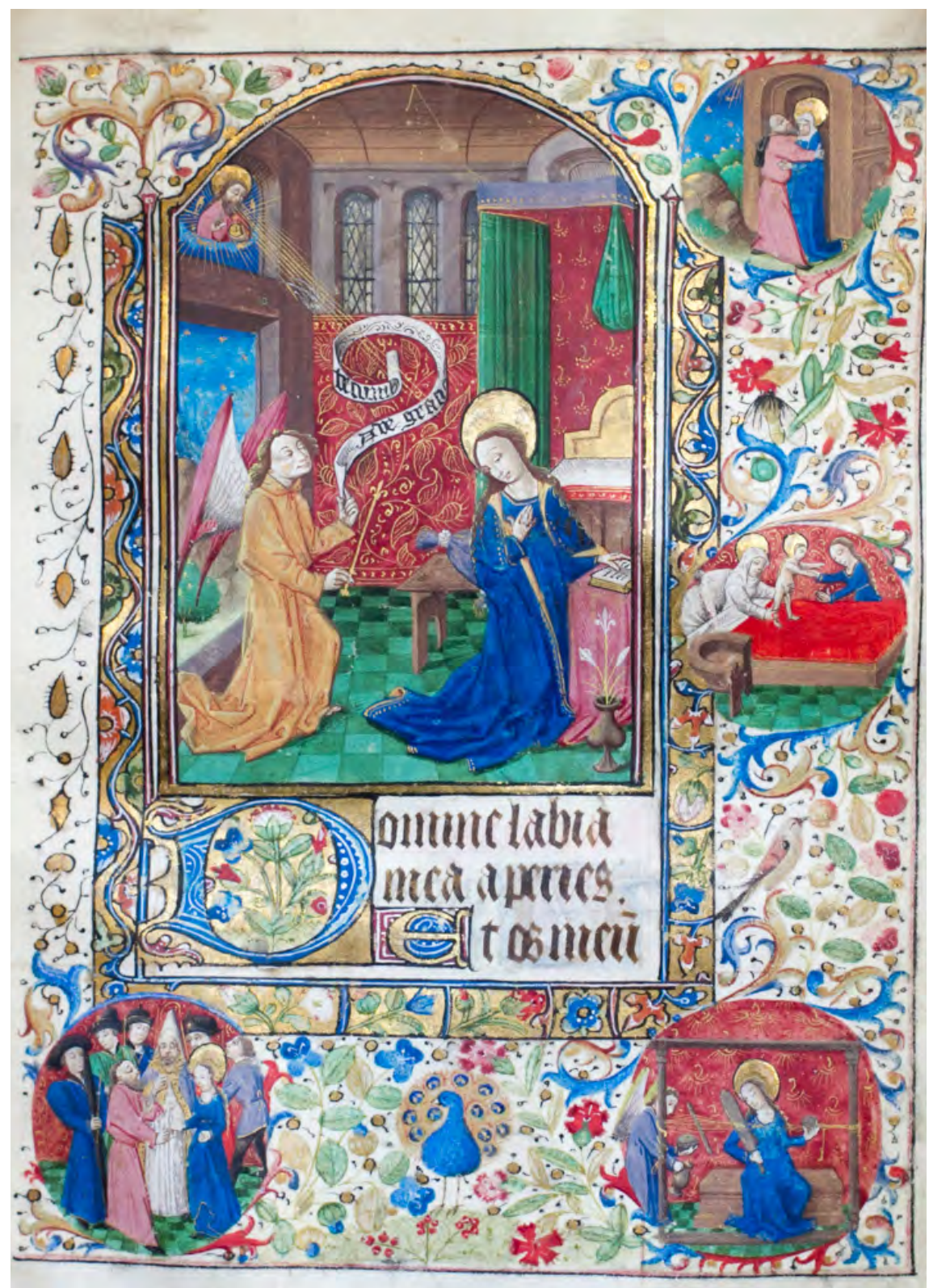

Fig. 6. Heures Lardanchet, l'Annonciation. Paris, Galerie Les Enluminures, BOH 114, fol. $28 \mathrm{r}^{\circ}$. (C) Les Enluminures. 


\subsubsection{La Présentation au Temple}

Pratiquement tous les manuscrits de notre échantillon ${ }^{85}$ comparatif, tout comme le ms. McGill 156 (fol. 59v $v^{\circ}$ ), reproduisent une composition similaire pour la scène de la Présentation au Temple. Une scène intime, à nombre réduit de personnages, est traversée de gauche à droite et de façon oblique par un autel de pierre aux reliefs rectangulaires souvent couvert d'une nappe blanche. L'autel sépare visuellement le groupe constitué de Marie, Jésus et Anne sur le devant de la scène et à gauche, du groupe constitué de Siméon et, accessoirement, d'un assistant, plus au fond et à droite. Siméon effectue un geste très caractéristique, en tendant ses mains recouvertes d'un lange vers l'enfant Jésus. La figure de Marie agenouillée, au visage renversé, enveloppant Jésus de son manteau, tandis que l'enfant s'agrippe à son cou de sa main droite, est pratiquement identique dans le ms. McGill 156 (fig. 7), les Heures Lardanchet (fig. 8), les Heures Habert du Berry d'Artois-Hoe et le Missel de Troyes (fig. 9) ; les variantes proposées par les Heures de Besançon, B. M., ms. 125 (fol. 40) ${ }^{86}$ et les Heures de New York, Pierpont Morgan Library, ms. M. 28 (fol. $\left.64 \mathrm{v}^{0}\right)^{87}$ semblent prendre un peu plus de liberté par rapport au modèle. Dans tous les manuscrits, un drap d'honneur aux rinceaux d'or sépare la scène de l'arrière-plan architectural constitué d'une suite de fenêtres grillagées prolongées par un plafond aux poutres visibles. L’expression générale de la scène traduit la soumission émue de Marie, de même que la tendresse attentive de Siméon envers un enfant inconnu, mais tant attendu. Constatons les mêmes problèmes d'exécution pour le ms. McGill 156 : plancher carrelé en perspective remplacé par une surface sans profondeur saturée de vert ; rinceaux d'or sur le drap d'honneur exécutés de façon assez grossière ; dessin maladroit de la forme tridimensionnelle de l'autel, etc.

85. Le Missel de Troyes, p. 471 ; les Heures Habert du Berry d'Artois-Hoe, p. 197, les Heures Lardanchet, fol. $81 v^{0}$.

86. http://www.enluminures.culture.fr/documentation/enlumine/fr/BM/besancon_052-01.htm. Site consulté le 5 mai 2015.

87. http://corsair.themorgan.org/cgi-bin/Pwebrecon.cgi?BBID=246503. Site consulté le 5 mai 2015. 


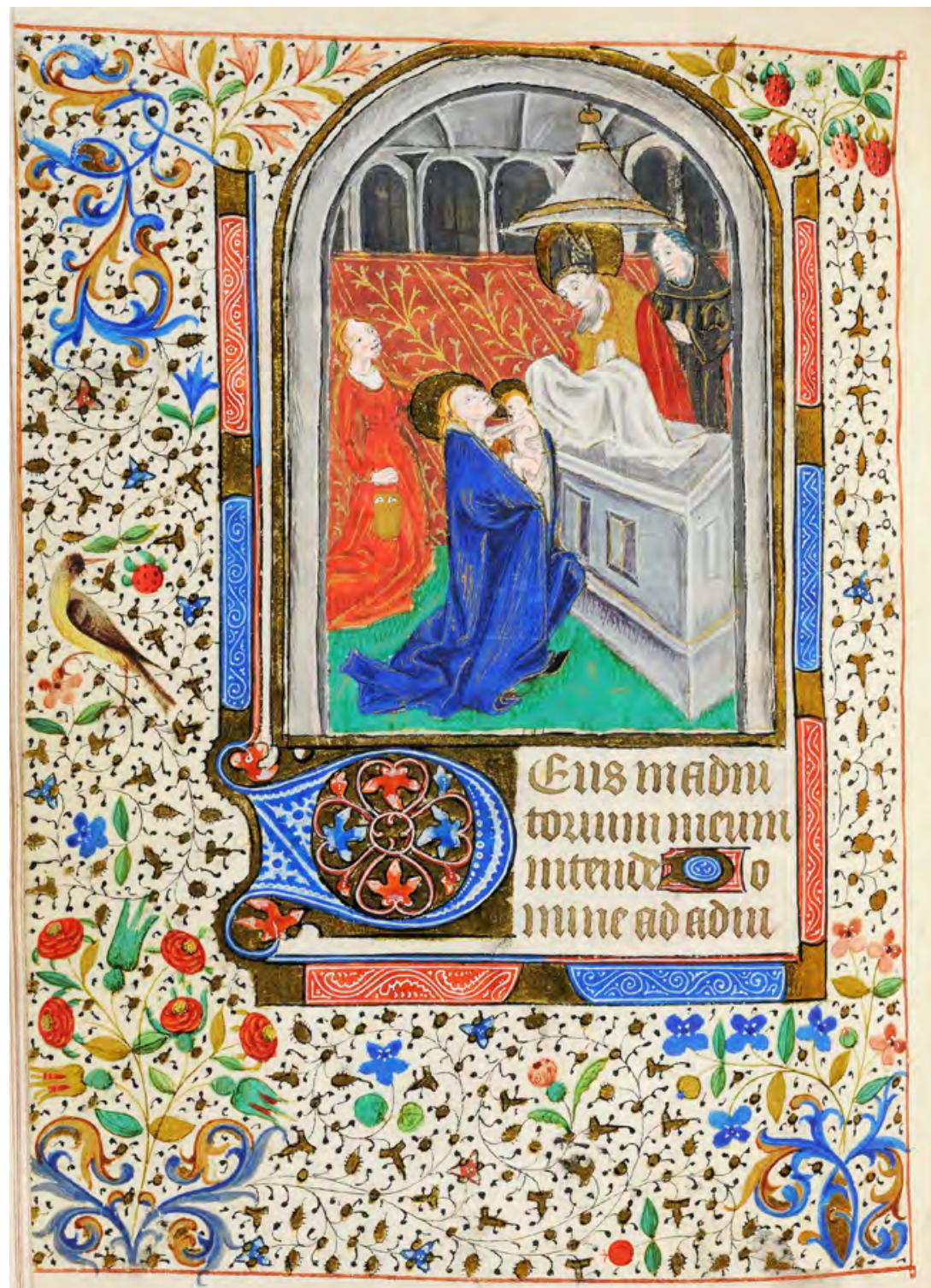

Fig. 7. Horae, la Présentation au Temple. Montréal, McGill, LRCS, MS 156, fol. 59vº. 


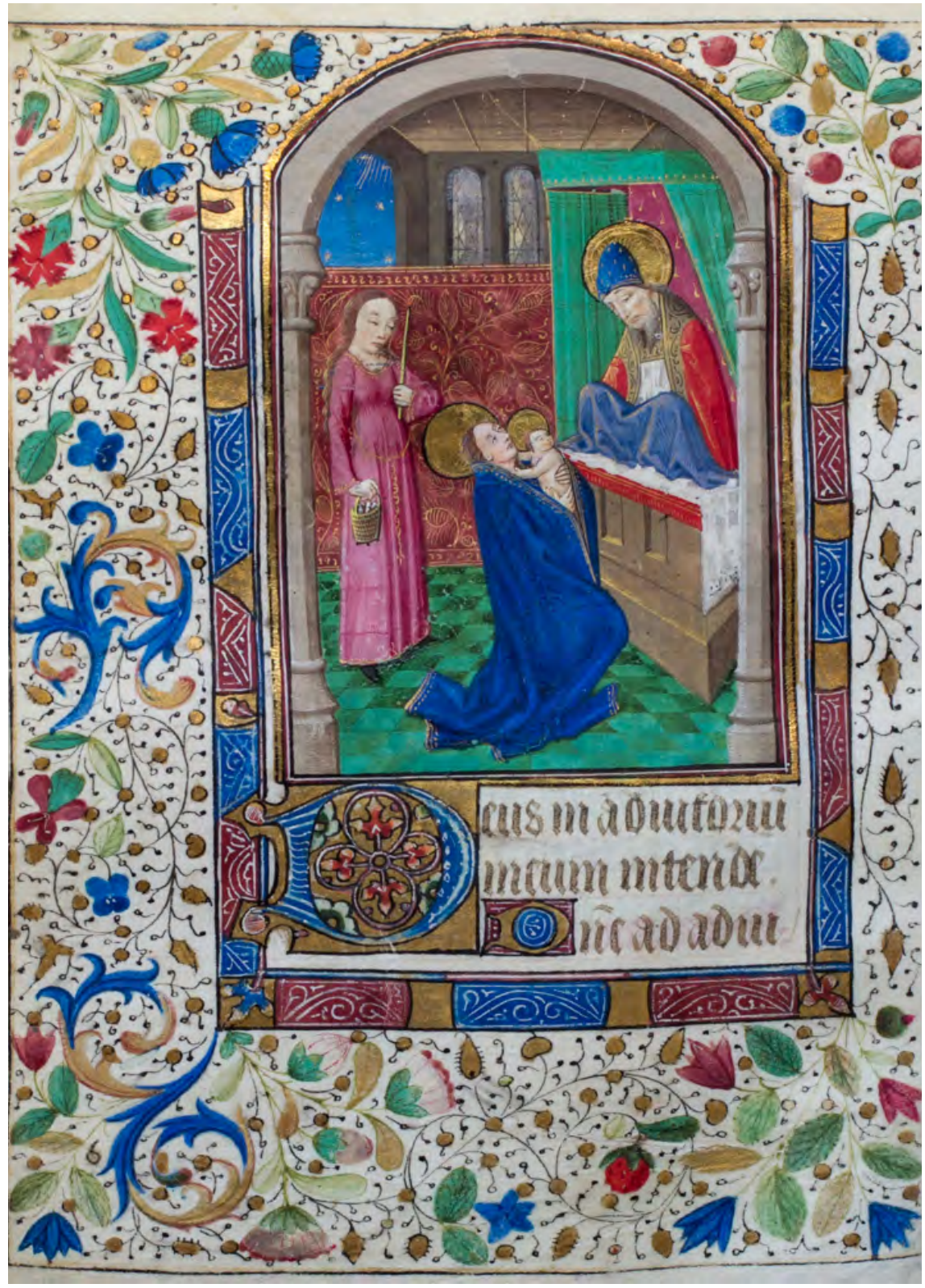

Fig. 8. Heures Lardanchet, la Présentation au Temple. Paris, Galerie Les Enluminures, BOH 114, fol. $81 v^{\circ}$. CLes Enluminures. 


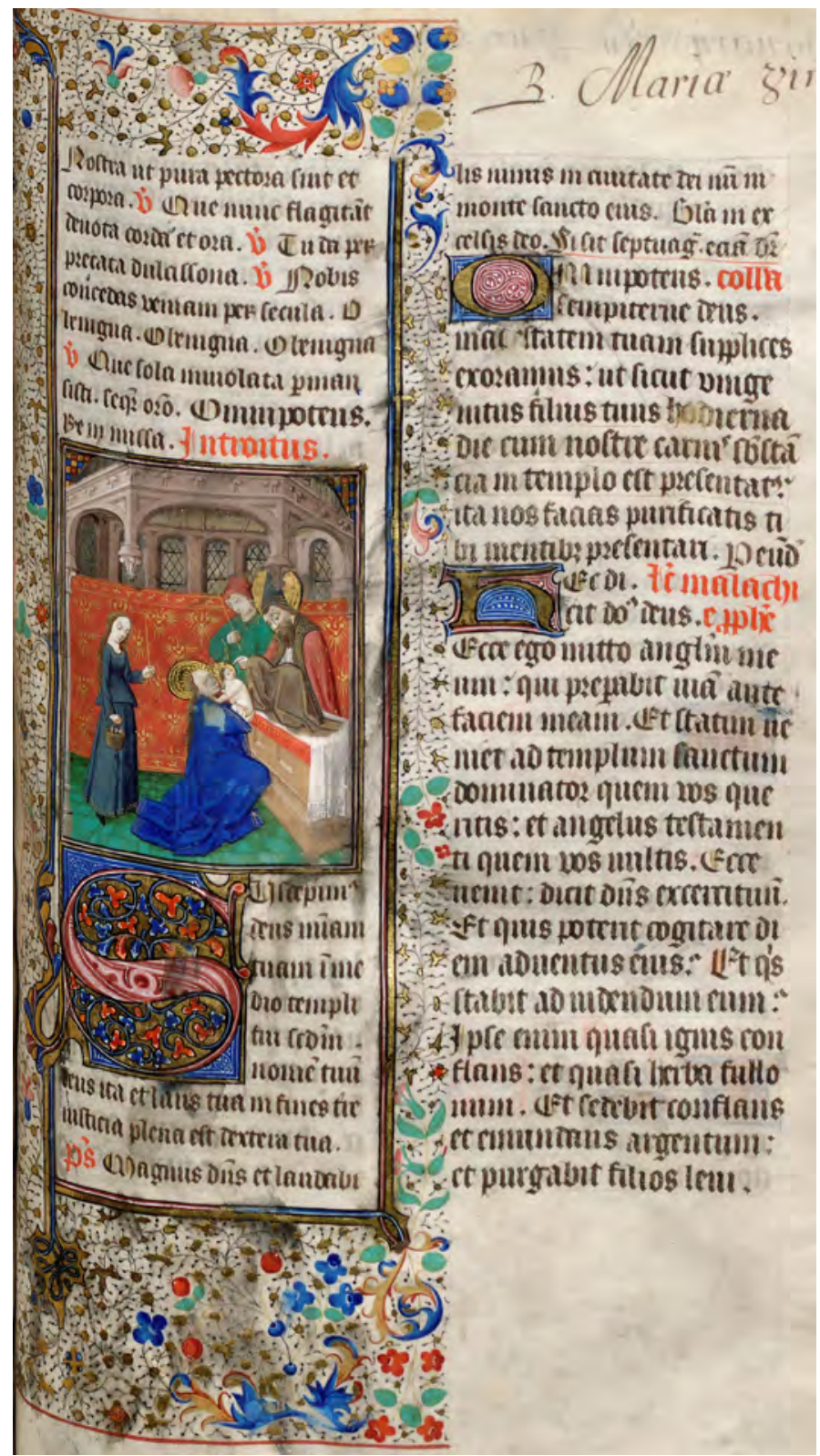

Fig. 9. Missel de Troyes, la Présentation au Temple. Paris, BnF lat. 865A, p. 471. (c) Bibliothèque nationale de France. 


\subsubsection{Le Couronnement de la Vierge}

Le traitement de la scène du Couronnement de la Vierge est très similaire dans le ms. McGill 156 (fol. 71 ro fig. 10) et les Heures Habert du Berry d'Artois-Hoe (p. 231) et se distingue peu de la variante proposée par le Missel de Troyes (p. 555) et les Heures Lardanchet (fol. 89r ${ }^{\circ}$, fig. 11). Marie, vêtue d'un grand manteau azur, est agenouillée devant Dieu en majesté. Celui-ci porte un manteau enveloppant rouge (bleu dans les Heures Lardanchet), une couronne (ou une triple couronne dans le Missel de Troyes et les Heures Habert du Berry d'Artois-Hoe) et un nimbe. De sa main droite, il bénit Marie ; dans sa main gauche, il maintient un orbe en or posé sur son genou gauche. Un ange en robe blanche à capuche et aux ailes blanches aux accents verts (bleus dans le Missel de Troyes) est en train de poser une couronne d'or sur la tête nimbée de Marie. Derrière ces trois personnages apparaît une dalle sculptée en pierre grise. La scène est limitée à l'arrière-plan par un drap d'honneur rouge à motifs géométriques dorés; un ou deux autres anges sont placés au-dessus de la tenture en attitude de vénération. Le tout se passe sous un ciel abstrait : doré ou en damier ${ }^{88}$. Encore une scène intime, soulignant l'élévation de Marie, son association aux mystères de la foi - l'un des thèmes essentiels du culte marial, tel que reflété dans les livres d'Heures.

Pour le ms. McGill 156, qui traite la scène en miroir, notons de nouveau l'absence de la perspective dans le traitement des éléments architecturaux (le trône, la dalle), le contour noir épais, l'exécution négligée des accents dorés. L'enlumineur semble vouloir imiter la fine voûte blanche qui délimite l'espace de l'image - cependant, le résultat n'a ni l'assurance des Heures Lardanchet, ni l'élégance des Heures Habert du Berry d'Artois-Hoe. Au contraire, on note plusieurs bavures et endroits non couverts par la peinture. Contrairement aux autres manuscrits, la main de Dieu bénissant la Vierge n'est pas retournée ${ }^{89}$.

88. Les Heures Habert du Berry d'Artois-Hoe proposent une présentation plus détaillée, incluant un paysage brumeux aperçu à travers une fenêtre et un ange - identique à celui de la scène de saint Jean sur Patmos - plongeant du ciel en posant la couronne sur la tête de Marie.

89. Voir également Lauga, $1: 204$. 


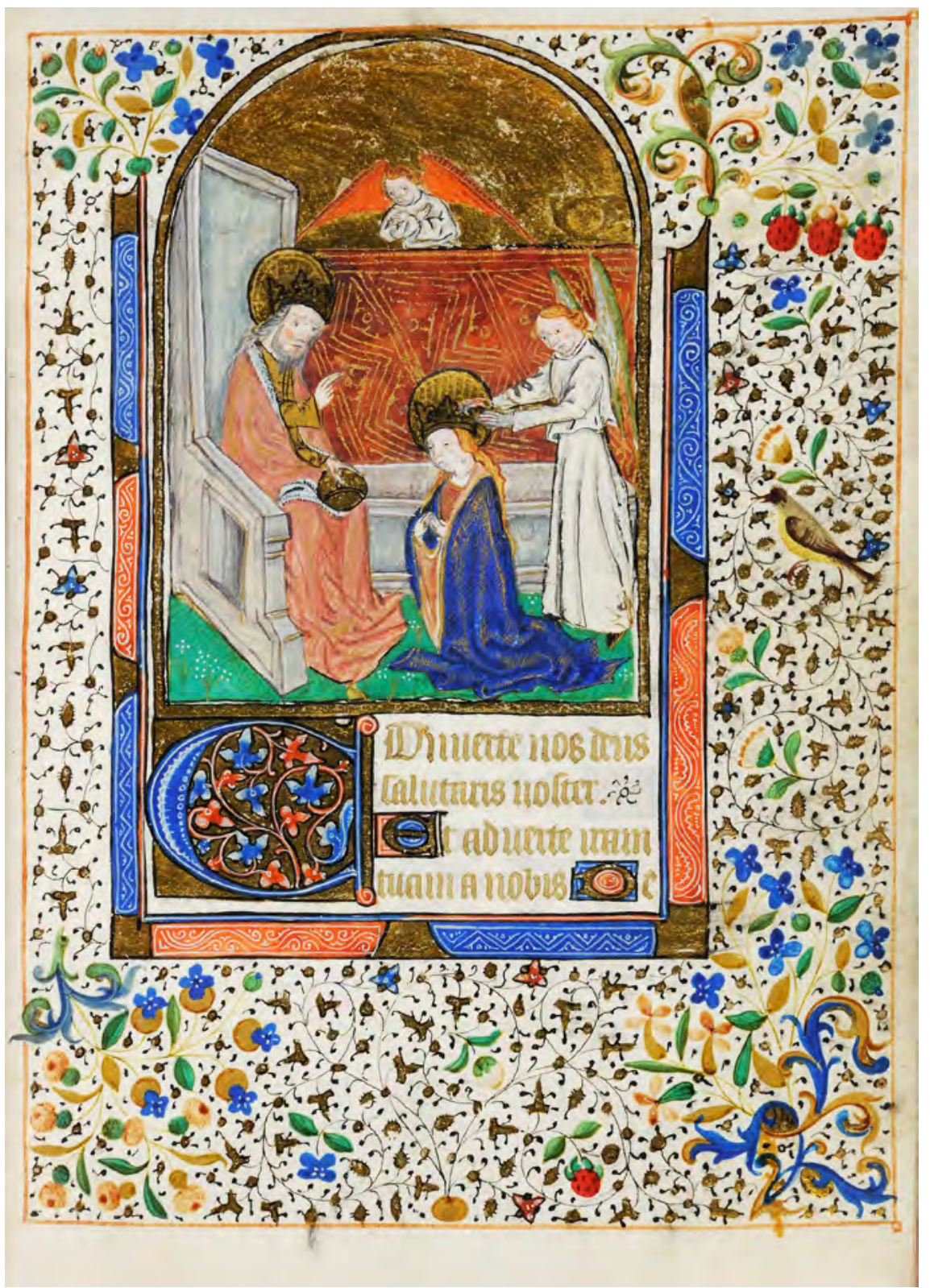

Fig. 10. Horae, le Couronnement de la Vierge. Montréal, McGill, LRCS, MS 156, fol. $71 r^{\circ}$. 


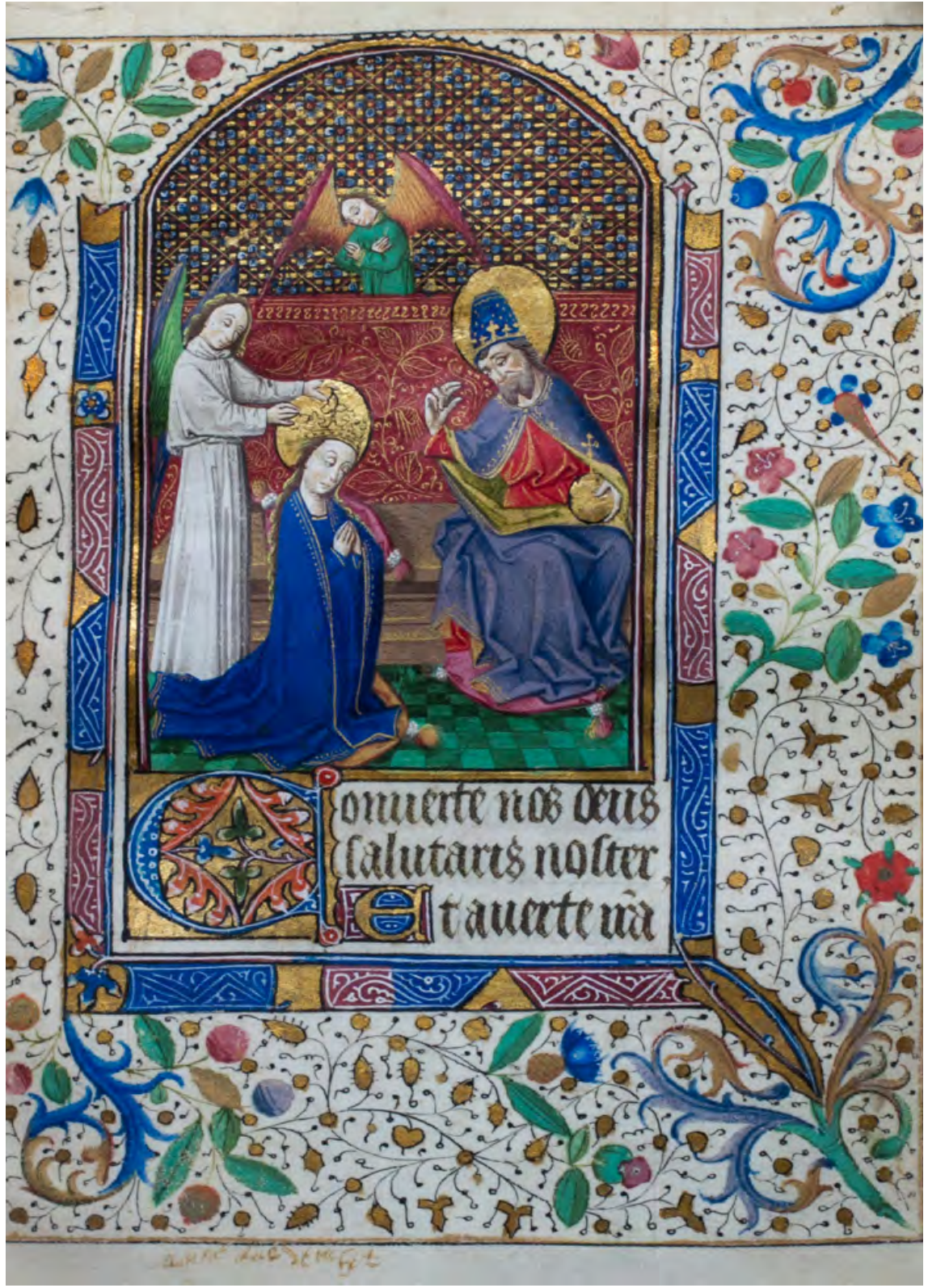

Fig. 11. Heures Lardanchet, le Couronnement de la Vierge. Paris, Galerie Les Enluminures, BOH 114, fol. 89r ${ }^{\circ}$. (c)es Enluminures. 


\subsubsection{David en prière}

Une autre scène significative est celle de David en prière. Ici, tous les manuscrits de notre échantillon, sauf le Missel de Troyes - qui l'exclut de son programme iconographique - conservent une même composition simple et dépouillée, mettant David agenouillé, vêtu d'une longue robe bleue et d'un manteau rouge fourré d'hermine, au centre d'un paysage champêtre aux structures architecturales isolées et repoussées vers l'horizon. Sa harpe et son chapeau pointu sont posés à terre à côté de lui (dans les Heures Lardanchet, fig. 13, sa couronne est enfilée tel un bracelet autour de son avant-bras droit). Son attitude générale, au visage renversé orienté vers Dieu le Père qui le regarde du ciel, est également révélatrice, tout comme la gamme rouge-azur de ses habits, par ailleurs assez simples. Il n'a pas de livre de prière devant lui, délaissant la prière " formelle ", " médiatisée » (à partir d'un livre, dans une chapelle), en faveur d'un rapt, une oraison directement adressée à Dieu, entrant en un véritable dialogue de gestes et de regards ${ }^{90}$.

Le ms. McGill 156 (fol. $75 \mathrm{r}^{\circ}$, fig. 12) se démarque de nouveau par ses maladresses. Citons l'uniformité du paysage vert, dont l'exécution ne rappelle en rien les paysages «flamands » du Maître du Missel de Troyes pourtant célébré pour la finesse et l'élégance de ses vastes panoramas bleutés ; l'absence du ciel en dégradé - également, l'une des marques distinctives de l'art du grand maitre ; ainsi que la décision de combler la courbe entre les deux masses rocheuses à l'arrière-plan par des édifices urbains aux dimensions peu compatibles avec les lois de la perspective. Le visage de David peut être rapproché du profil de l'un des saints de la Pentecôte dans les Heures Carruel ${ }^{91}$.

90. La variante des Heures Habert du Berry d'Artois-Hoe (p. 253), place le roi pénitent tournant le dos à un autel avec un livre posé et le fait contempler le même ange blanc, ici brandissant l'épée du châtiment divin ; cependant, l'idée du rapt n'est pas abandonnée.

91. Les Heures Carruel, fol. 14 ro, reproduction dans König, Tour de France, $1: 264$, pl. IV. 


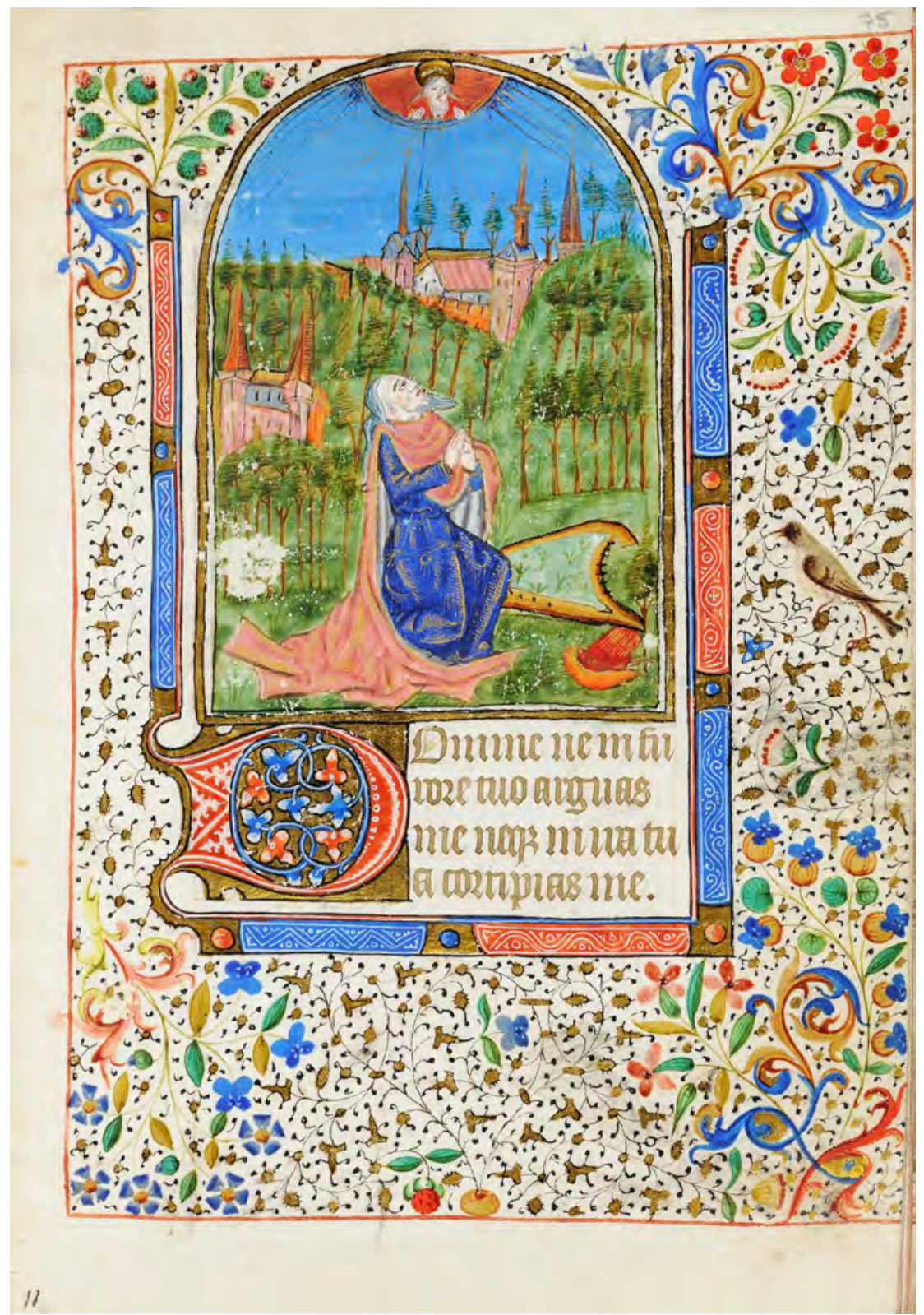

Fig. 12. Horae, David en prière. Montréal, McGill, LRCS, MS 156, fol. 75r ${ }^{\circ}$. 


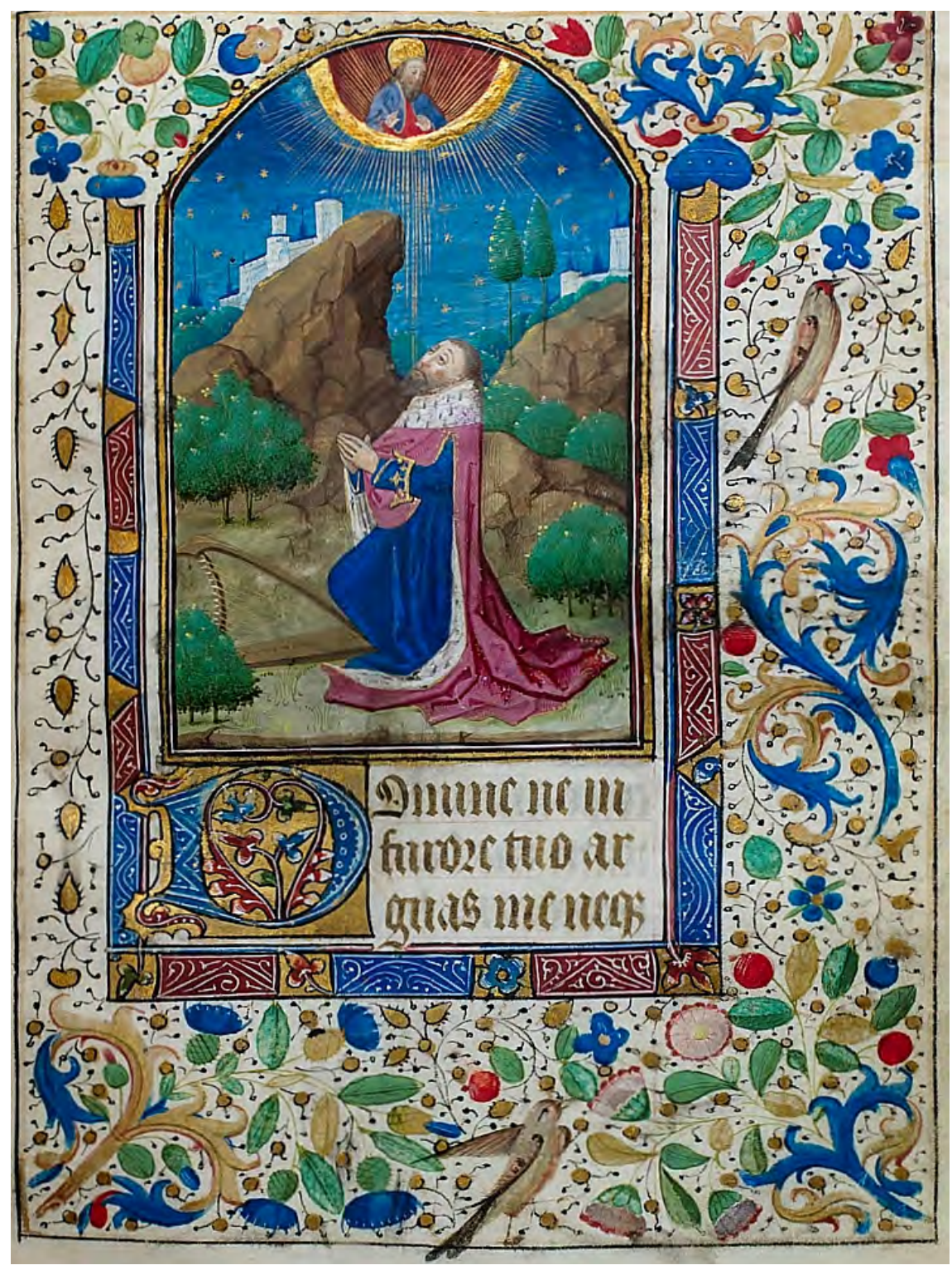

Fig. 13. Heures Lardanchet, David en prière. Paris, Galerie Les Enluminures, BOH 114, fol. $95 r^{\circ}$. (C) Les Enluminures. 


\subsubsection{La Nativité}

Le thème de la Nativité offre une diversité de mises en scène dans les manuscrits attribués au maître du Missel de Troyes. Cependant, plusieurs éléments stylistiques permettent d'en dégager les éléments communs. Ainsi, les quatre manuscrits de référence ${ }^{92}$ proposent le même traitement de la figure de Marie agenouillée, tête inclinée, mains jointes, en attitude d'adoration de l'enfant. La position de Joseph dans le ms. McGill 156, le Missel de Troyes et les Heures Lardanchet est identique ; toutefois, notre artiste introduit une variante en plaçant dans la main gauche du personnage un coin de tissu transparent recouvrant l'enfant. Le drap somptueux qui couvre le lit de Marie et qui se prolonge amplement sur le sol, servant de lange au nouveau-né, constitue une trouvaille stylistique propre au Maître du Missel de Troyes. Les autres similitudes incluent la mangeoire rectangulaire en pierre ainsi que les plessis secs tressés délimitant la scène, qu’on trouve également dans les Heures Habert du Berry d'Artois-Hoe et les Heures de Troyes 3897. Notons aussi la présence, dans tous les manuscrits, d'un dais au-dessus du lit de Marie soulignant le contraste entre la pauvreté absolue de l'étal abritant la famille et la naissance « royale » de l'enfant Jésus.

Si l'artiste du ms. McGill 156 (fig. 14) suit son modèle pour la composition de l'image, il y propose une palette de coloris radicalement différents, privilégiant les couches épaisses des couleurs blanche et grise pour le drap du lit, qui est rouge dans tous les autres exemples, ainsi que le dais, qui est bleu étoilé partout ailleurs. Il choisit l'or pour la robe de Marie - un choix similaire dans les Heures Lardanchet, tandis que dans les autres manuscrits, la robe est de bleu royal tout comme le manteau - et l'orange éclatant pour l'habit de Joseph, qui est plutôt rose dans les Heures Lardanchet (fig. 15), les Heures de Troyes 3897 et le Missel de Troyes. La figure de l'enfant Jésus semble avoir subi des corrections au moment de son exécution, les contours de son corps ayant été retracés à plusieurs reprises. La couverture translucide est également une particularité du ms. McGill 156.

92. Le Missel de Troyes, p. 34 ; les Heures Habert du Berry d'Artois-Hoe, p. 154, les Heures de Troyes 3897 , fol. $35 v^{\circ}$, les Heures Lardanchet, fol. $66 v^{\circ}$. 


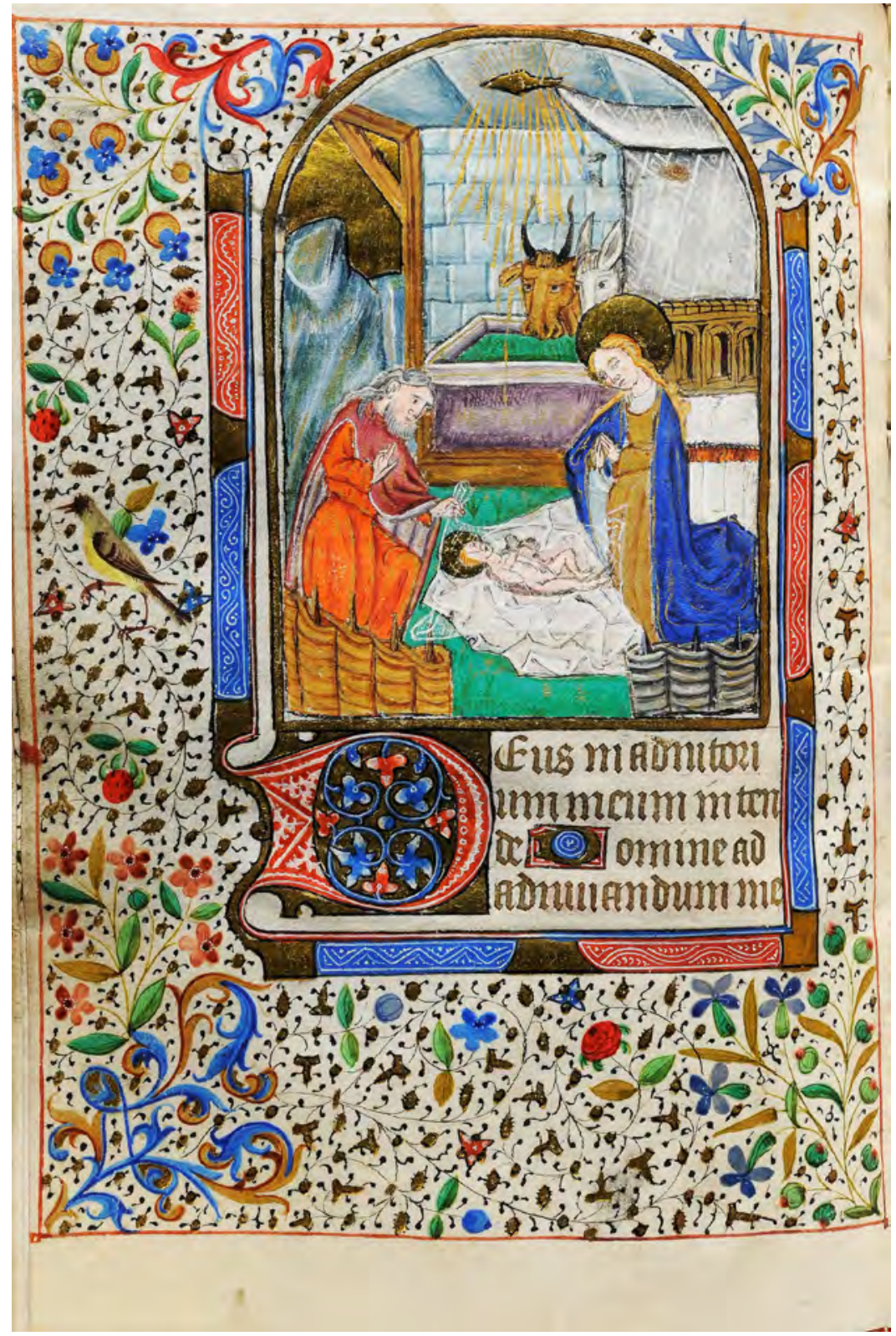

Fig. 14. Horae, la Nativité. Montréal, McGill, LRCS, MS 156, fol. 47vº. 


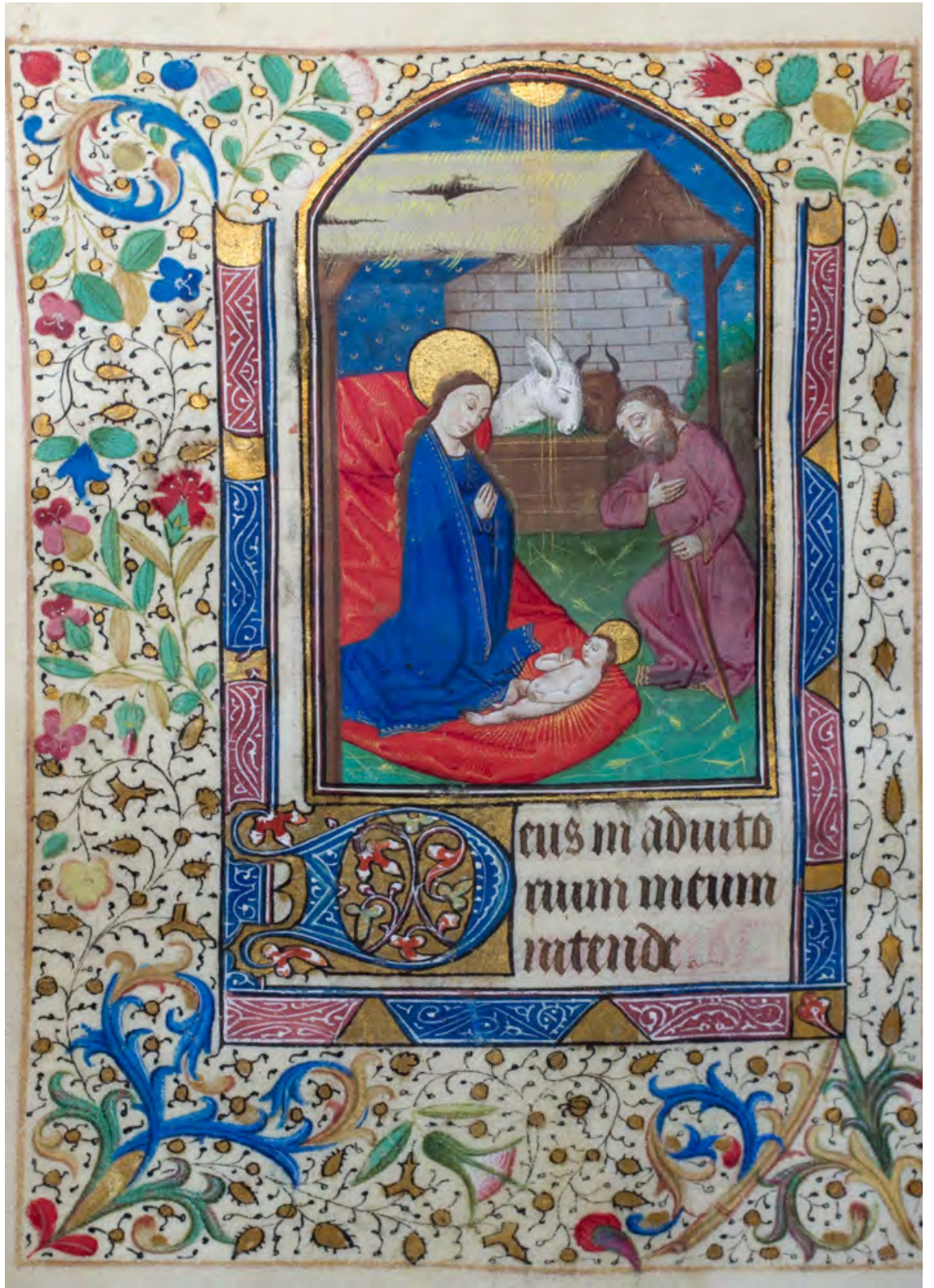

Fig. 15. Heures Lardanchet, la Nativité. Paris, Galerie Les Enluminures, BOH 114, fol. $66 v^{\circ}$. (CLes Enluminures. 


\subsubsection{La Fuite en Égypte}

La Fuite en Égypte est une autre scène qui accuse des similitudes entre le ms. McGill 156 (fol. 64ror , fig. 16) et les œuvres du Maître de Missel de Troyes, à commencer par la composition générale de la scène qui se concentre exclusivement sur les personnages principaux, sans tenir compte de la richesse narrative de l'épisode biblique. Les manuscrits de référence ${ }^{93}$ reproduisent visiblement le même modèle en ce qui concerne les gestes caractéristiques des personnages - le manteau de Marie croisé sur ses genoux et enveloppant l'enfant blotti contre son sein, la position des mains de Joseph tenant la bride dans la main droite et la canne avec sa besace dans la main gauche ${ }^{94}$, ainsi que la posture de l'âne. Le tracé du terrain accidenté qui forme l'arrière-plan est identique dans le ms. McGill 156 et les Heures Lardanchet (fig. 17). De nouveau, l'artiste du ms. McGill 156 introduit plusieurs variantes importantes au niveau de la palette : un habit rose pour Joseph, une chemise dorée pour l'enfant qui ne semble pas être emmailloté, la couleur jaune ocre pour mettre en valeur le sentier que suivent les personnages, la couleur bleue uniforme en couche épaisse sans effet de dégradé pour le ciel, le gris aux lourds accents blancs pour l'âne. Le contour noir et les accents dorés aux traits épaissis sont omniprésents. L'artiste choisit de couvrir de verdure le rocher massif à gauche de l'image et introduit des édifices lourds, sans respect des lois de la perspective, à gauche et à droite de l'image.

93. Les Heures Habert du Berry d'Artois-Hoe, p. 211, les Heures de Troyes 3897, fol. 52r ${ }^{\circ}$, les Heures Lardanchet, fol. $85 \mathrm{v}^{\circ}$.

94. Les Heures de Troyes 897 introduisent ici une variante ; de même, le terrain à l'arrière-plan est traité selon un tracé différent de celui du ms. McGill 156 et les Heures Lardanchet. 


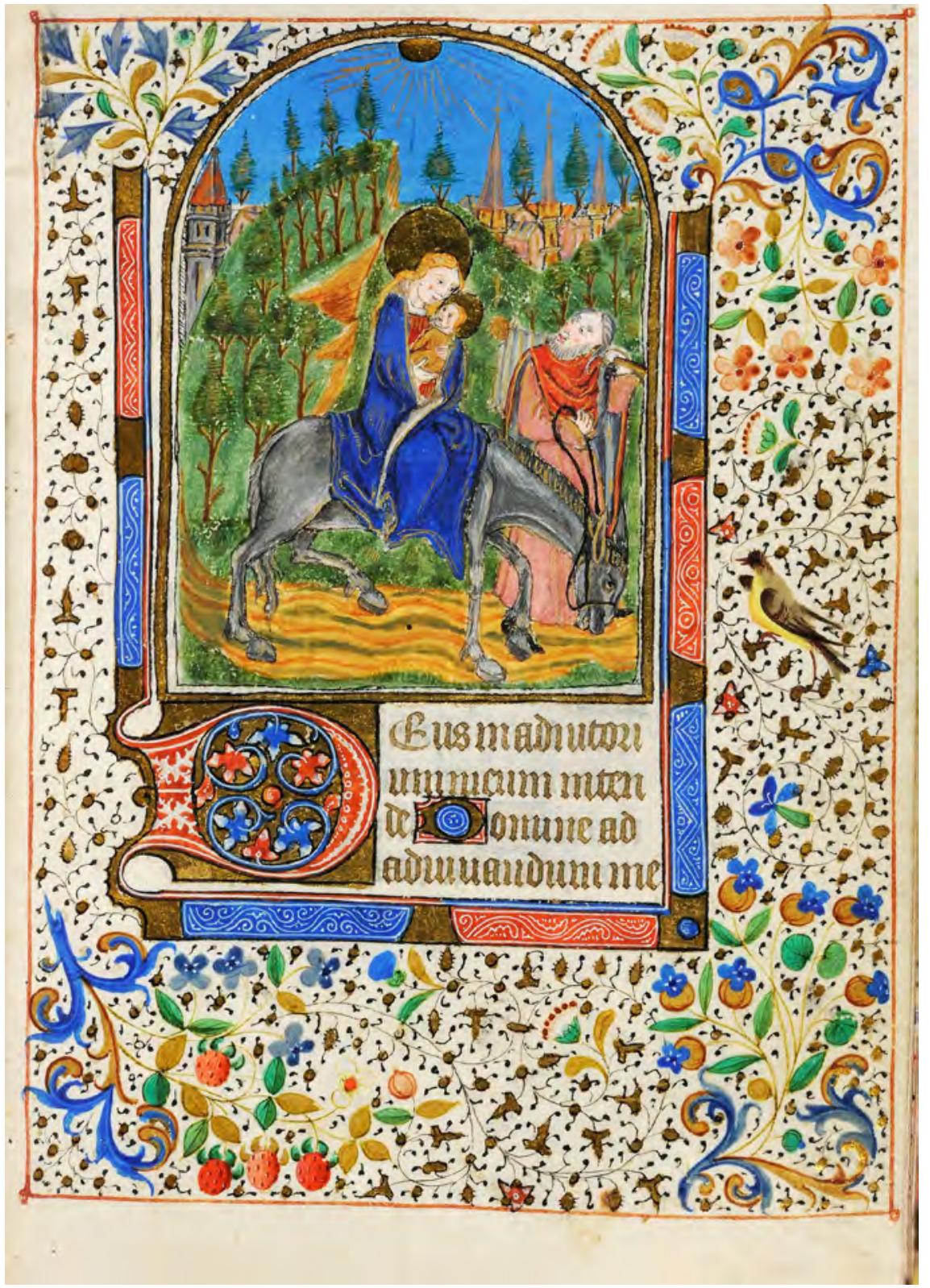

Fig. 16. Horae, la Fuite en Égypte. Montréal, McGill, LRCS, MS 156, fol. 64rº. 


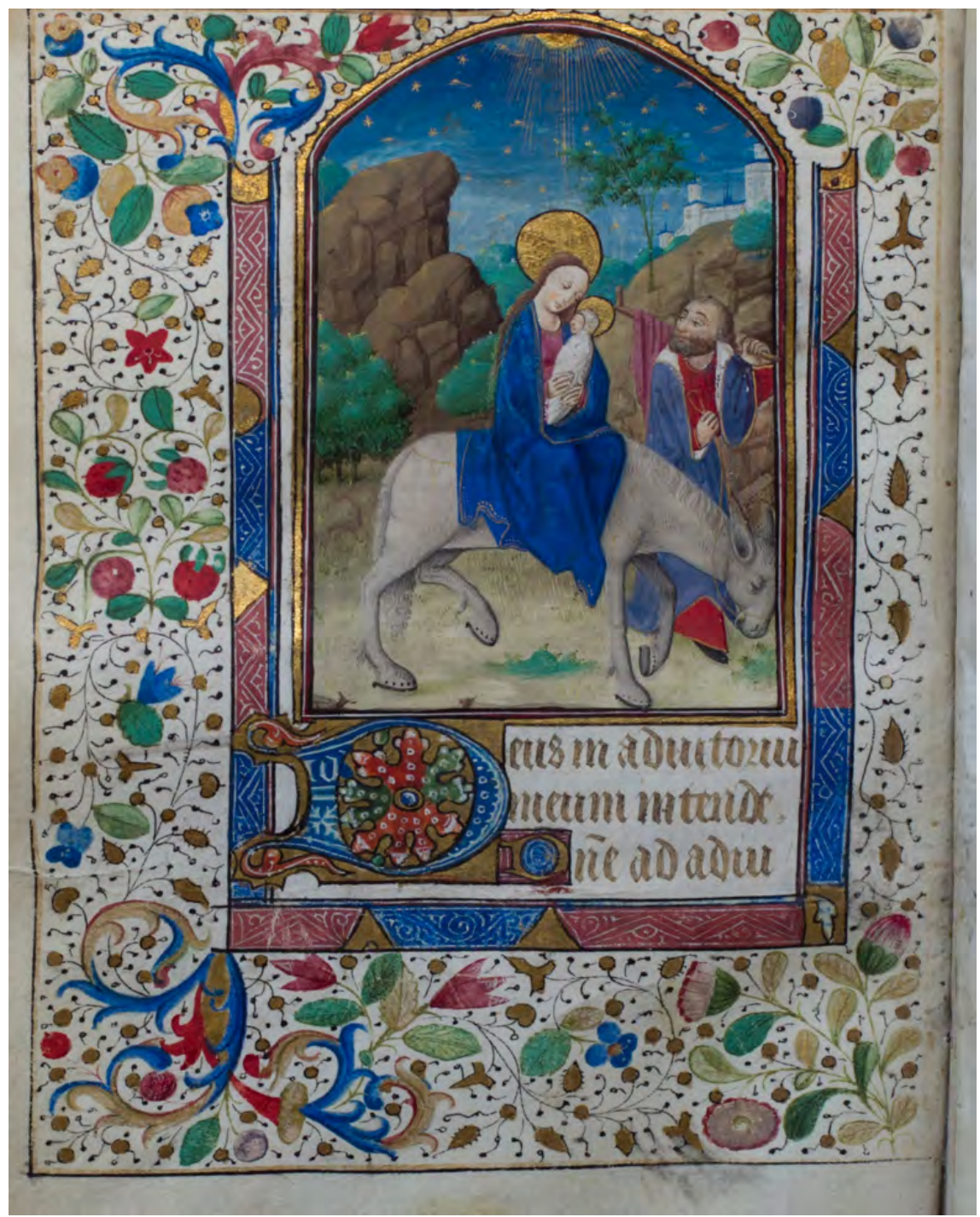

Fig. 17. Heures Lardanchet, la Fuite en Égypte. Paris, Galerie Les Enluminures, BOH 114, fol. 85v $v^{\circ}$. (cLes Enluminures. 


\subsubsection{La Messe funéraire}

L'image accompagnant l'Office des morts dans le ms. McGill 156 (fol. 99r fig. 18), se démarque par l'absence d'un modèle clairement identifiable dans les autres manuscrits attribués au Maître du Missel de Troyes. Une telle image ne fait pas partie du programme iconographique du Missel de Troyes, tandis que les autres manuscrits de notre corpus choisissent l'enterrement au cimetière pour accompagner ce texte ${ }^{95}$. Cependant, le ms. McGill 156 démontre des similitudes de composition avec le manuscrit Kentucky 2008.4, fol. 124ro surtout dans la disposition des officiants et des deuillants, séparés par le lourd lutrin et le cercueil couvert et confinés dans l'espace étroit de l'église ${ }^{96}$. L'exécution de l'image démontre les mêmes simplifications et maladresses que l'ensemble d'enluminures du ms. McGill 156.

\subsection{L'attribution artistique du ms. McGill 156}

L’analyse comparée des enluminures et des bordures a pu démontrer avec un degré de certitude significatif l'existence d'une filiation décorative et iconographique directe entre le manuscrit McGill 156 et un certain nombre des manuscrits attribués au Maître du Missel de Troyes de la première période de sa carrière. Les bordures des cahiers 3-16 de notre manuscrit démontrent, tant par leur style que par leur exécution, une appartenance claire et non-équivoque à la production de l'atelier de ce maître, de même que, dans le cas des miniatures, l'utilisation des compositions provenant tout droit des "images de stock " de l'atelier. Néanmoins, l'écart considérable de la maîtrise des techniques picturales et parfois de la palette choisie par l'artiste enlumineur par rapport

95. Ce sont les Heures Habert du Berry d'Artois-Hoe, p. 401, les Heures Lardanchet, fol. 124r ${ }^{\text {o. Citons }}$ également les Heures de Marseille, Bibliothèque municipale, ms. 112, fol. 161r ${ }^{\circ}$; les Heures de Pierpont Morgan ms. M 28, fol. 111r ${ }^{\circ}$; le Missel de Charles de Neuchâtel, Auckland, Auckland City Librairies, Special Collections, Med. MSS G. 139, p.42; les Heures de Besançon, B. M., ms. 125, fol. 65r'. La scène est absente dans le Missel de Troyes et les Heures de Troyes 3897.

96. Ce livre d'Heures à l'usage de Besançon, bien que présentant quelques similitudes stylistiques avec les horae issues de l'atelier du maître du Missel de Troyes, a été daté des années 1430-1440. Les chercheurs modernes associent son style à celui du maître de Bousicaut et du Maître du Bréviaire de Jean sans Peur. Il est consultable sous forme d'une présentation grand public sur le site http://www. speedmuseum.org/book_of_hours/ (site consulté le 25 octobre 2015). Peut-on attribuer la composition de l'image à une tradition bisontine préexistante à l'activité du Maître du Missel de Troyes ? 


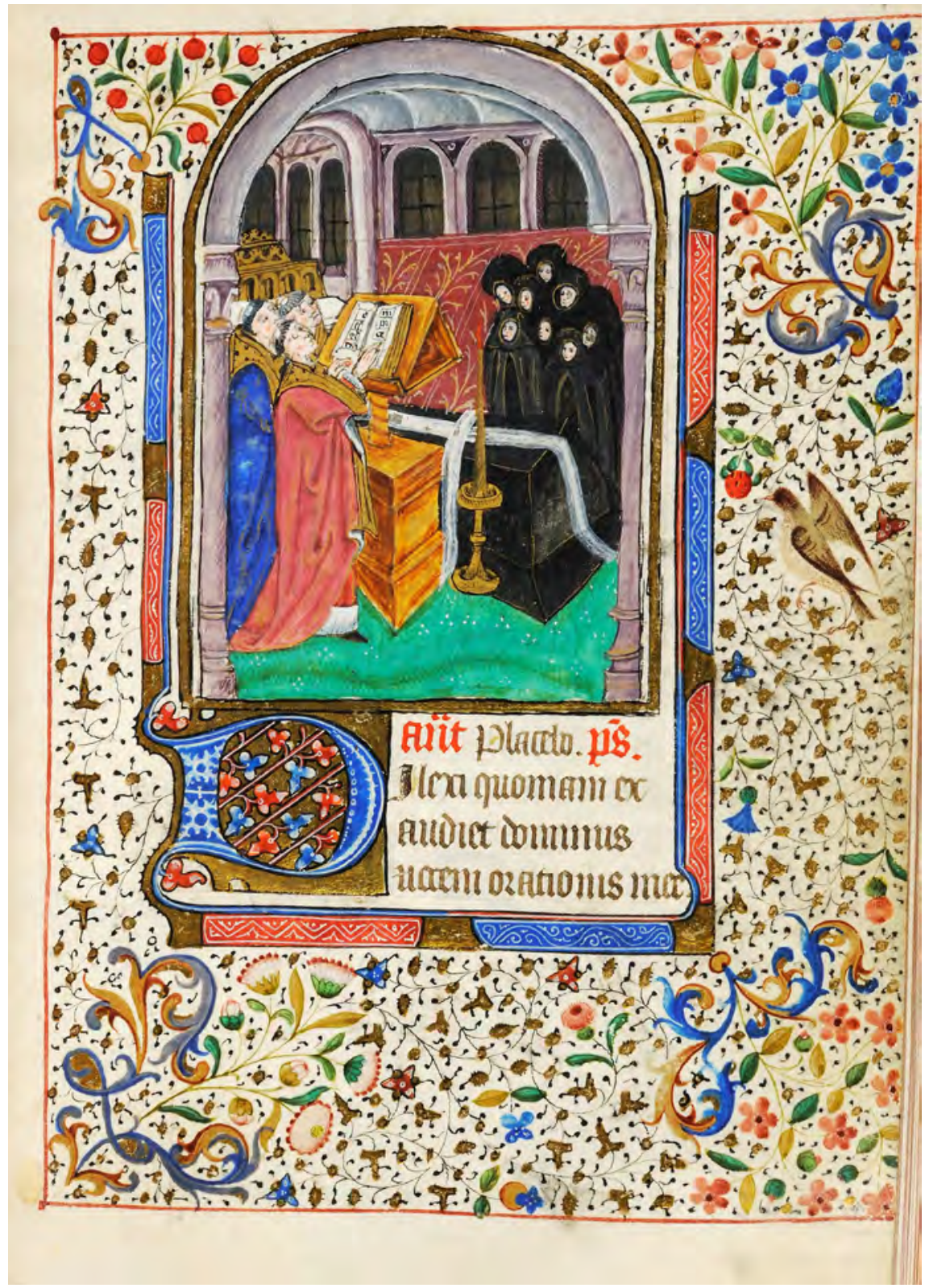

Fig. 18. Horae, Messe funéraire. Montréal, McGill, LRCS, MS 156, fol. 99rº. 
au reste du corpus artistique attribué au Maître du Missel de Troyes ne nous permet pas d'y reconnaître sa main.

Peut-on mieux définir les modalités de l'élaboration du ms. McGill 156 ? Plusieurs scénarios semblent possibles. Les seize premiers cahiers de l'actuel ms. McGill 156, copiés et décorés dans l'atelier du maitre, enluminures tracées et prêtes à recevoir la couleur, auraient été laissés de côté jusqu'à l'ajout de l'unité codicologique manquante, c'est-à-dire la fin de l'Office de morts et les suffrages. Au moment de l'assemblage final du manuscrit, un collaborateur mineur, possiblement un apprenti, ou même l'auteur des bordures des cahiers 17-22, se serait chargé d'en compléter le décor et l'iconographie selon les « images de stock » disponibles.

Une autre hypothèse est également envisageable : le ms. McGill 156 serait une copie épigone d'un manuscrit stylistiquement très proche des Heures Lardanchet. Nous connaissons au moins un précédent dans le cas du Missel de Saint-Jean-au-Marchép ${ }^{97}$. Copiant à l'identique les bordures et deux des images du Missel de Troyes, ce manuscrit, exécuté pour un bourgeois de la ville de Troyes Jean de La Ruelle accuse, malgré la volonté affirmée de reproduire son modèle, une certaine rudesse dans l'exécution des visages - plus touffus que l'original, aux paupières rondes et aux iris élargis, assez semblables à ceux du ms. McGill 156 - ainsi que le traitement simplifié des personnages secondaires, surtout des animaux et du paysage, les accents dorés peu soignés ${ }^{98}$. Le ms. McGill 156, serait-il dû à un petit enlumineur cherchant à reproduire les modèles élaborés par le grand maître de l'enluminure troyenne?

Quoi qu'il en soit, notre manuscrit affirme une volonté de se rattacher à une tradition artistique pleine de vitalité qui caractérise la région troyenne au $\mathrm{XV}^{\mathrm{e}}$ siècle - une tradition qui allie les meilleurs modèles parisiens du premier tiers du siècle aux nouveautés stylistiques flamandes et dont le Maître du Missel de Troyes offre un exemple des plus originaux ${ }^{99}$.

97. Avril, Très riches heures de Champagne, 126-129.

98. Voir la discussion dans Lauga, $1: 213$.

99. Avril, Très riches heures de Champagne, 43 et Lauga, 1 : 202-203. 


\section{Conclusion}

$\mathrm{Au}$ terme de cette recherche, dont certains éléments resteront - peut être encore longtemps - non élucidés, nous espérons avoir soulevé le couvert d'anonymat sous lequel, jusqu'à présent, se cachait ce manuscrit complexe. Plus particulièrement, nous avons pu avancer des hypothèses concernant son usage liturgique, sa datation et son affiliation artistique. L'identification de sa décoration et de son iconographie aux modèles propres à l'atelier du Maître du Missel de Troyes s'est avérée un argument décisif par la consolidation de ces hypothèses, car la provenance troyenne du manuscrit - du moins à l'étape de la copie et de la décoration des bordures des seize premiers cahiers - informe de façon importante ses composantes cultuelle et liturgique.

Ainsi, une telle attribution vient justifier et renforcer les affinités troyennes relevées dans le calendrier ${ }^{100}$. Les connotations bisontines indéniables des litanies, de l'Office de la Vierge, de l'Office des morts, ainsi que d'une partie des suffrages, constituent une autre balise géographique. La communauté religieuse dont l'usage est reflété dans notre manuscrit, se situerait-elle aux confins du diocèse de Troyes et de celui de Besançon?

Ceci étant dit, la diversité géographique des cultes relevés dans l'hagiographie du ms. McGill 156 transcende la définition étroite de l'« usage ». En effet, plusieurs de ces cultes - souvent associés aux institutions religieuses célébrées comme lieux de pèlerinage - confèrent à ce livre d'Heures une dimension de "pèlerinage intérieur ", une invitation aux prières ancrées dans des espaces géographiques concrets tout comme dans l'histoire du salut.

Par ailleurs, l'assemblage des unités codicologiques distinctes constaté dans ce manuscrit, remet en question sa datation proposée par Wysocki et Méhu et basée uniquement sur la présence de Bernardin de Sienne dans les suffrages. À fortiori, le caractère "supplémentaire " des suffrages à ce saint permet de situer l'élaboration de la majeure partie de ce livre d'Heures avant l'instauration de son culte en 1450. Par ailleurs, cet assemblage, les additions textuelles faites parfois selon les principes de compilation, le caractère composite de la décoration définissent ce livre d'Heures comme un livre « mouvant », un 
livre qui se complète, se réinvente, se corrige. Cette vitalité intérieure, faite de surprises et de contradictions, fascine autant qu'elle déroute.

Malgré toutes ces complexités et contradictions, le ms. McGill 156 revendique indéniablement sa place dans les grandes traditions artistiques qui se développent à l'époque dans les régions de l'Est de la France. Il témoigne plus particulièrement de l'engouement considérable pour l'art d'un grand peintre de ce siècle qui cherche de nouveaux moyens d'expression artistique tout en préservant la tradition de " migration de modèles » ${ }^{101}$ qui accorde un rayonnement durable aux résultats de ses trouvailles. Ce grand artiste, le Maître du Missel de Troyes, attend encore son historien.

En dépit des qualités artistiques parfois inégales, le ms. McGill 156 offre toute une gamme d'outils décoratifs servant à transformer ce livre usuel en un véritable objet d'art - l'art de la bordure avant tout autre. Ce livre d'Heures permet également de réfléchir à la longue histoire des manuscrits médiévaux, ainsi qu'à leur intérêt artistique et culturel pour les artistes collectionneurs européens et surtout britanniques du $\mathrm{XIX}^{\mathrm{e}}$ siècle, grande époque de redécouverte de l'art du Moyen Âge, tout comme pour la modernité.

\section{Annexe I : l'Office de la Vierge du ms. McGill 156}

\begin{tabular}{|c|c|c|}
\hline$\underline{\text { Ad Matutinum }}$ & [Ps.94] & Invitatorium Ave Maria \\
\hline \multicolumn{2}{|c|}{ Hymnus : Quem terra pontus } & Ant. ps. 8 : Benedicta tu \\
\hline \multicolumn{2}{|c|}{ Lectio i. : O mater virgo virginum } & $\begin{array}{c}\text { Responsorium i. : Sancta et } \\
\text { immaculata }\end{array}$ \\
\hline \multicolumn{2}{|c|}{ Lectio ii. : O stella maris } & R. (ii.) : Beata es Maria \\
\hline \multicolumn{2}{|c|}{ Lectio iii. : O fili caste virginis } & R. (iii.) : Felix namque es \\
\hline \multicolumn{3}{|l|}{ [Fin des Matines manquante] } \\
\hline Ad Laudes [début manquant] & $\begin{array}{c}\text { Ps. 92, 99, 62, 66, } \\
\text { Benedictus }\end{array}$ & \\
\hline \multicolumn{2}{|c|}{ Antiphona : $\mathrm{O}$ admirabile } & \\
\hline
\end{tabular}

101. François Avril, «Les copies à répétition. À propos de la circulation et de la dissémination des modèles ", in Tributes to Jonathan J. G, Alexander. The Making and Meaning of Illuminated Medieval and Renaissance Manuscripts, Art and Architecture, éd. Susan L'Engle et Gerard B. Guest (Londres : Harvey Miller Publichers, 2006), 127-140. 


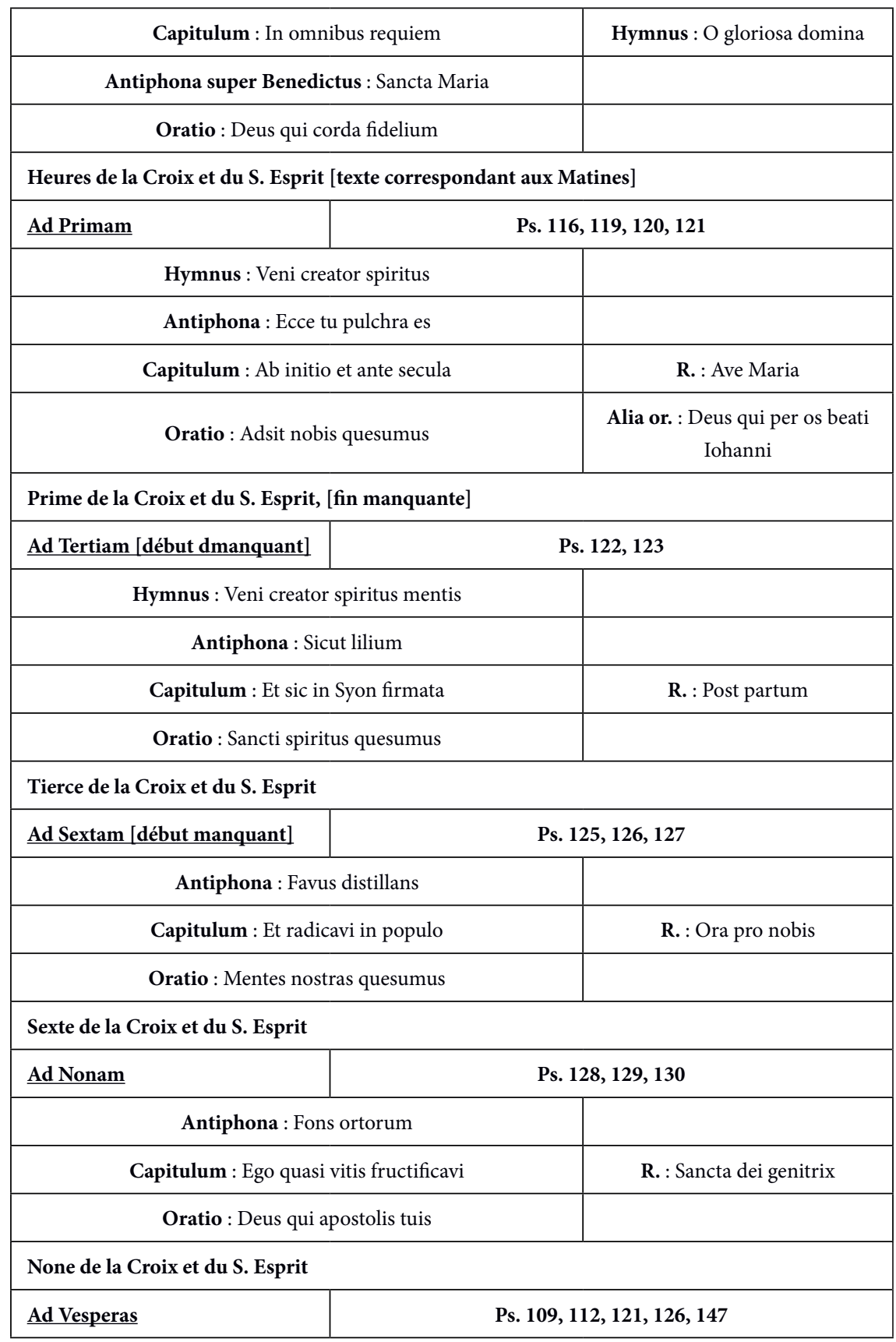




\begin{tabular}{|c|c|}
\hline Antiphona : O beata mater & \\
\hline Capitulum : Beata es virgo Maria & Hymnus : Ave maris stella \\
\hline Antiphona super Magnificat : Rogamus te & \\
\hline Oratio : Deus qui corda fidelium & \\
\hline Vêpres de la Croix et du S. Esprit & Ps. 131, 132, 133 \\
\hline Ad Completorium & Hymnus : virgo singularis \\
\hline Antiphona : Cum iocunditate & \\
\hline Capitulum : Sicut cynamomum & \\
\hline Antiphona super Nunc dimittis : Salve regina & \\
\hline Oratio : Ure igne sancti spiritus & \\
\hline
\end{tabular}

\section{Structure typique des Heures de la Vierge à l'usage de Besançon ${ }^{102}$}

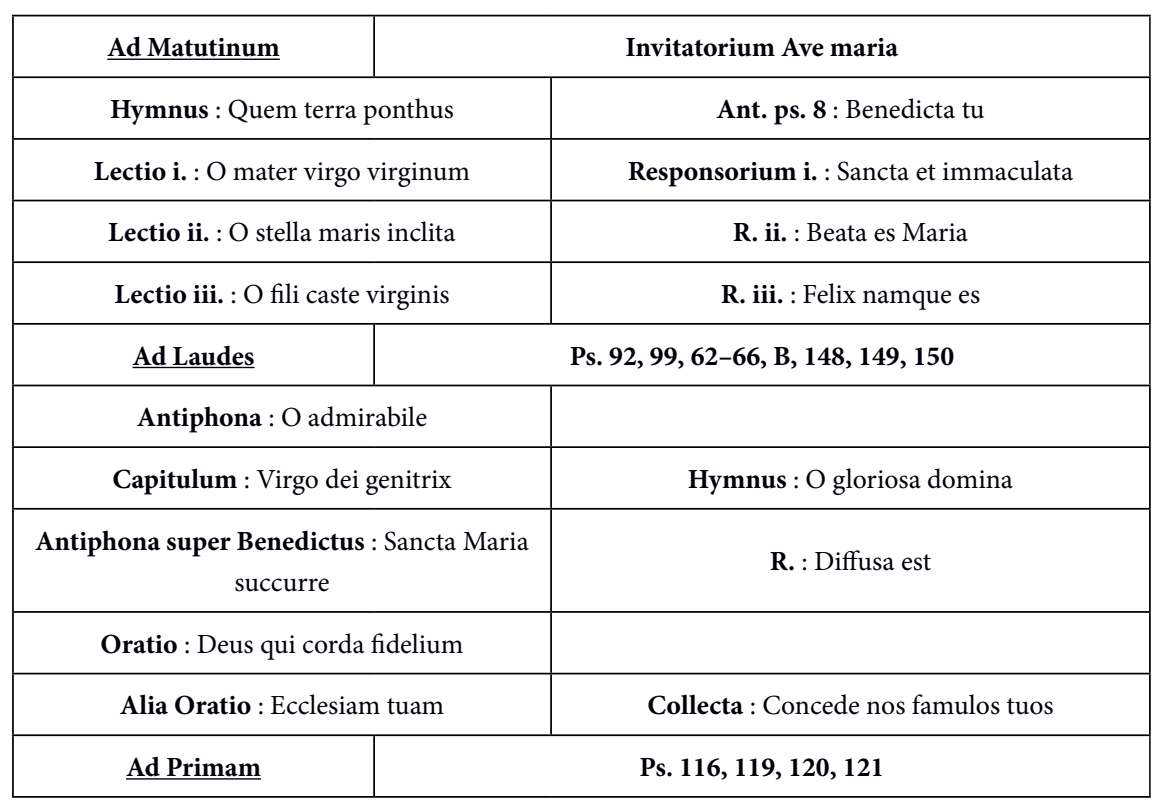

102. E. Drigsdahl note quelques variantes par rapport à ce modèle, et notamment, l'usage du chapitre Sicut cynamomum à l'heure de Complies dans plusieurs manuscrits bisontins. 


\begin{tabular}{|c|c|c|}
\hline \multicolumn{3}{|c|}{ Hymnus : Veni creator spiritus } \\
\hline \multicolumn{3}{|c|}{ Antiphona : Ecce tu pulchra es } \\
\hline \multicolumn{2}{|c|}{ Capitulum : Ego quasi vitis } & R. : Ave maria \\
\hline \multicolumn{2}{|c|}{ Oratio : Sancti spiritus } & V. : Benedicta tu \\
\hline \multicolumn{2}{|c|}{$\begin{array}{l}\text { Alia Oratio : Deus qui beati iohannis } \\
\text { apostoli }\end{array}$} & Collecta : Deus qui virginalem aulam \\
\hline$\underline{\text { Ad Tertiam }}$ & & Ps. 122, 123, 124 \\
\hline \multicolumn{3}{|c|}{ Hymnus : Veni creator spiritus } \\
\hline \multicolumn{3}{|c|}{ Antiphona : Sicut lilium } \\
\hline \multicolumn{2}{|c|}{ Capitulum : Ab initio et ante } & R. : Post partum \\
\hline \multicolumn{2}{|c|}{ Oratio : Adsit nobis quesumus domine } & V. : Dei genitrix \\
\hline \multicolumn{2}{|c|}{$\begin{array}{l}\text { Alia Oratio : Deus qui [apostolos] beati } \\
\text { iohannis }\end{array}$} & Collecta : Famulorum tuorum \\
\hline$\underline{\text { Ad Sextam }}$ & & Ps. 125, 126, 127 \\
\hline \multicolumn{3}{|c|}{ Antiphona : Favus distillans } \\
\hline \multicolumn{2}{|c|}{ Capitulum : Et sic in syon } & R. : Ora pro nobis \\
\hline \multicolumn{2}{|c|}{ Oratio : Mentes nostras quesumus } & V. : Ut digni \\
\hline \multicolumn{2}{|c|}{$\begin{array}{l}\text { Alia Oratio : Sancti quesumus domine beato } \\
\text { iohannes }\end{array}$} & Collecta : Concede misericors deus fragilitati \\
\hline Ad Nonam & & Ps. 128, 129, 130 \\
\hline \multicolumn{3}{|c|}{ Antiphona :Fons ortorum } \\
\hline \multicolumn{2}{|c|}{ Capitulum : Et radicavi } & R. : Sancta dei genitrix \\
\hline \multicolumn{2}{|c|}{ Oratio: Mentibus nostris quesumus domine } & V. : Intercede \\
\hline \multicolumn{2}{|c|}{ Collecta : Protege nos famulos tuos } & V. : Exaltata est \\
\hline \multicolumn{3}{|c|}{$\begin{array}{l}\text { Alia Oratio : Beati iohannes apostoli tui et } \\
\text { euuangelista }\end{array}$} \\
\hline$\underline{\text { Ad Vesperas }}$ & & Ps. 109, 112, 121, 126, 147 \\
\hline \multicolumn{2}{|c|}{ Antiphona : Beata mater } & \\
\hline
\end{tabular}




\begin{tabular}{|c|c|}
\hline Capitulum : Beata es virgo maria & R. : Xpi virgo dilectissima \\
\hline Hymnus : Ave maris stella & $\mathrm{V} \cdot$ Ouoniam peccatorum \\
\hline $\begin{array}{l}\text { Antiphona super Magnificat : Rogamus te } \\
\text { virgo virginum }\end{array}$ & V. : Post partum R.Dei genitrix \\
\hline \multicolumn{2}{|l|}{ Oratio : Deus qui corda fidelium } \\
\hline Alia Oratio : Ecclesiam tuam & Collecta : Concede nos famulos tuos \\
\hline Ad Completorium & Ps. 131, 132, 133 \\
\hline \multicolumn{2}{|l|}{ Antiphona : Cum iocunditate } \\
\hline \multicolumn{2}{|l|}{ Hymnus : Virgo singularis } \\
\hline Capitulum : Paradisi porta & R. : Benedicta tu \\
\hline $\begin{array}{l}\text { Antiphona super Nunc dimittis : Salve } \\
\text { regina misericordie }\end{array}$ & V. : Et benedictus \\
\hline \multicolumn{2}{|l|}{ Oratio : Ure igne sancti spiritus } \\
\hline Alia Oratio : Beati iohannes apostoli & Collecta : Gratiam tuam quesumus domine \\
\hline
\end{tabular}

\section{Annexe II : structure des Matines de l'Office des morts du ms. McGill 156}

Verset : Dirige domine deus meus

Leçon I : Parce michi domine

Répons : Credo quod Redemptor

Verset : Quem uisurus sum ego ipse et non alius

Leçon II: Tedet animam meam vite mee

Répons : Qui Lazarum

Verset : Requiem eternam dona eis domine

Leçon III : Manus tue fecerunt te et plasmaverunt me

Répons : Domine quando veneris

Verset : In loco pascue

Leçon IV : Responde michi quantas habeo iniquitates

Répons : Heu michi, Domine

Verset : Anima mea turbata est

Leçon V : Homo natus de muliere breui uiuens tempore

Répons : Ne recorderis peccata mea 
Verset : Dirige domine deus meus in conspectu tuo uiam meam

Leçon VI : Quis michi hoc tribuat ut in in inferno protegas me

Répons : Peccantem me cotidie et non me penitentem

Verset : Deus in nomine tuo saluum me fac

[changement d'unité codicologique]

Leçon VII : Spiritus meus attenuabitur : dies mei breuiabuntur

Répons : Peccantem me cotidie et non me penitentem

Verset : Deus in nomine tuo saluum me fac

[Leçon] VIII : Pelli mee consumptis carnibus adhesit os meum

Répons : Memento mei deus quia uentus est uita mea

Verset : Et non reuertetur oculus meus ut uideat bona

Leçon IX : Uir fortissimus iudas. Colatione facta duodecim milia dragmas

argenti misit ${ }^{103}$

Répons : Libera me domine de morte

Verset : Dies illa dies ire calamitatis et miserie

Verset : Requiem eternam dona eis domine.

103. Cette leçon est relevée par Knud Ottosen, The Responsories and Versicles of the Latin Office of the Dead (Norderstedt : Books on Demand, 2007), 64, groupe 1f, qui la trouve dans les sources ambroisiennes, les traditions des villes de Metz et de Langres, ainsi que les offices clunisiens. 